\title{
Forecasting the price of crude oil
}

\author{
Ramesh Bollapragada ( Akash Mankude • \\ V. Udayabhanu
}

Accepted: 12 May 2021/Published online: 6 August 2021

(C) Indian Institute of Management Calcutta 2021 predict crude oil prices for 1991 through 2017. We tried several variations of the base model and the best method produced MAD, MSE, MAPE and MPE of $12.676,280.92,0.2597,0.028$, respectively. We further estimated the forecasts of the oil prices at a monthly level based on our yearly forecast of oil prices from our best method. The calculated MAD, MSE, MAPE and MPE values are 5.66, 82.1163, 0.1246 and 0.038 , respectively, which shows our model is promising again at a monthly level.

Keywords Crude oil · Price $\cdot$ Forecasting ·

Simulation

\section{Introduction}

Crude oil is a mixture of hydrocarbons that exist in liquid phase in natural underground reservoirs and remain liquid at atmospheric pressure after passing through surface separating facilities. It is both an important source of fuel and a raw material for many products such as nylon, tires, CD cases and plastic and is present in almost all aspects of our lives and therefore, plays a significant role in how our economy changes. Thus, the changes in crude oil prices are often great indicators as to changes in the overall economy and global markets. However, forecasting the price of oil accurately is difficult across various time periods as there are a multitude of factors that can affect the prices of oil. 
As an example, during the US Recession of 2008, the housing crisis caused the price of crude oil to drop, rendering many forecasting models ineffective in predicting future changes. More recently, the onset of the COVID-19 pandemic in early March 2020 led to a significant decrease in demand for crude oil. When the representatives of OPEC + (the informal alliance of OPEC and non-OPEC countries) met to discuss oil production cuts, Russia, a non-OPEC member of the summit refused the demands to cut production, leading to an oil price war against OPEC countries, and in particular Saudi Arabia, causing the prices of crude oil to plummet dramatically.

These unpredictable actions and events can cause dramatic effects on the prices of crude oil, which in turn can affect the global economy and markets. The ability to forecast these changes in oil prices allows economic participants such as firms to adapt to future market changes and provides decision makers with accurate information with which they can use to select the optimal decision for them. As such, it is vital that we develop a robust model that can forecast the prices of oil and these changes as accurately as possible. To develop a model for forecasting crude oil price, we follow the below five steps in this paper. First, the primary theories related to the forecasting of oil price and its advantages and disadvantages are discussed. Second, the Target Capacity Utilization (TCU) rule is chosen as the framework to forecast the oil price. We present revisions to the application of TCU rule to fit to our experiments. Third, historical data from 1986 through 2017 are used to develop a multiple regression model. Fourth, combined with the multiple regression model, the recursive simulation method is used to generate predicted crude oil prices from 1991 through 2017. And finally, the results are compared to actual values to evaluate the accuracy of the developed forecast models.

\section{Literature review}

Many economists realized the necessity to formulate models that could accurately forecast the price of oil, following the oil embargo and the exploitation of the oil prices after the Arab-Israel conflict of 1973. Since then, multiple oil forecasting models have been published. This paper will extensively review one specific model, the Target Capacity Utilization Rule as well as other models. Our paper uses the TCU rule with regression to forecast the crude oil prices with the data from 1987 to 2017. In addition, we develop several other new forecasting models in this paper.

Target capacity utilization rule

The basic idea of the Target Capacity Utilization (TCU) rule assumes that the Organization of Petroleum Exporting Countries (OPEC) can adjust the oil price according to its capacity utilization rate due to the world's dependency on oil supply from OPEC. When used to forecast oil price, the TCU rule is often combined with recursive simulation, one of the system simulation methods.

Although it makes economic sense, the application of it lacks sound economic theory as a foundation. Many economists can only explain the application of the TCU rule by the "rule of thumb."

Baumol and Quandt (1964) pointed out that humans rarely behave as economic theories suggest. In contrast, their behaviors are largely influenced by experiences, an idea also noted by Sterman (1987, 1989). It is difficult to model human behavior. Moreover, the distortion, misuse, lagged dissemination, and different interpretation of information also violate the basic assumptions in traditional economic models. Therefore, the behaviors can be predicted if the experiences are understood. If the observed variables can be quantified, the procedure is easy, the cost is affordable, and the result can be replicated, the use of rule of thumb is a feasible way to predict behavior. Unlike an economic model, a rule of thumb is used to determine the function, not a best solution. This function is also called a behavior function under the system simulation method. Additionally, the system simulation method does not have the same assumptions that the economic models include, making more suitable for today's crude oil market (Powell 1990).

Although the behavior function derived from the TCU rule varies from model to model, most models use regression to capture the relationship between the change of oil price and the rate of capacity utilization (Energy Modeling Forum 1992). For instance, in the Oil Market Simulation Model, 1992 (OMS'92 Model) by the department of energy, and the Crude Oil Projection Model by Stanford Research Institute (1991), a general function: $\Delta P / P=\alpha+\beta \cdot(1 /$ $(1-\mathrm{UT}))$, where $\Delta P / P$ is the percentage change of price, $\mathrm{UT}$ is the capacity utilization rate, and $\alpha$ and $\beta$ are 
regression coefficients, is used to express the relationship. This function is also called the price reaction function.

The main flaw of the TCU rule is the lack of a strict mathematical inference procedure (Refer to Powell (1990), Gately (1983) and Suranovic (1993) for details). Powell (1990) suggests that more explanatory variables be included in the price reaction function to improve the predicting power. He further pointed that the result will vary considerably, if other parameters are used. While in agreement with the composition of the price reaction function, Bacon (1991) states that capacity utilization is not the only factor that concerns OPEC.

Suranovic (1993) examines the result from the system simulation model and from economic models, which use profit maximization as an objective. He found that by using system simulation to set the oil prices, the profit is smaller than that from an economic model. However, the difference is not significant after the profits are discounted. Furthermore, the forecasted prices generated from the economic model are highly variable, not as stable as those from the system simulation model. Thus, using the TCU recursive simulation model to forecast oil price is more appropriate than using an economic model.

\section{Exhaustible resources theory}

The Exhaustible Resources Theory plays an important role in the area of natural resources research. According to Houthakker (1983), the idea of exhaustible resources theory was first presented by Javon in 1865 . However, the complete theoretical framework had not been developed until the method of calculus of variations was introduced by Hotelling (1931). Following the oil crisis in 1973, Solow used the principles of this related theory into research on oil markets.

The general idea of exhaustible resources theory is that as the stock of resources decrease and user costs, Hotelling Rent, ${ }^{1}$ increase, the oil prices will increase.

\footnotetext{
${ }^{1}$ Hotelling rent, or scarcity rent, is the difference between the marginal cost of producing (extracting) a nonrenewable resource and the market price charged. In a seminal 1931 article in the Journal of Political Economy, Hotelling hypothesized that this scarcity rent would increase at the market rate of interest until a point in time when the resource is exhausted. This can be shown to be socially optimal (in the absence of market failures). This theory is known in resource economics as "Hotelling's Rule."
}

However, after the oil price dramatically decreased in 1986, forecast models based on exhaustible resources theory faced serious challenges. Devarajan and Fisher (1981) indicate that when the final production is based on future cost and price, the predicted cost and price should not be used to predict the usage of stock resource.

Powell (1990) also mentioned that exhaustible resources models emphasize the assumption of perfect information, but the uncertain future information does not satisfy this assumption. In addition, a typical exhaustible resources model often focuses on the longterm outcomes and cannot explain short to midterm unrealistic outcomes in the model.

Adelman (1990) states that from an economic point of view, high cost will reduce the investment on the resources or even the abandoning of their use. Moreover, through his knowledge of oil production, he found that as the difficulty of extracting oil increases, it is the increasing marginal cost, not "Hotelling Rent," which will cause oil price to rise. Most importantly, oil prices rarely follow the predictions of the exhaustible resources model.

\section{Other forecasting models}

Alquist et al. (2011) sought a reliable forecasting model for real and nominal oil prices in order to benefit all oil-importing and exporting countries. For nominal prices, they tested a wide range of methods and focused on the ability of monthly and daily oil futures prices to forecast the nominal price. For the real price, they considered alternative methods of forecasting like random walk, AR and ARMA models, and the no-change forecast and tried to prove that vector autoregressive models (VAR) are more accurate than the random-walk forecast and others at short horizons.

The results of the paper exhibit the difficulty to reconcile the different results of the literature. They realized that there are many parameters, such as the definition of the oil price variable, whether one used nominal or real prices, the time periods of evaluation, how the forecast accuracy is evaluated, etc. However, the paper provided strong evidence that the nominal oil price predictability was consistent with economic theory. They also found that over a short horizon, a specifically designed VAR model was more accurate than the no-change forecast. 
Alquist et al. (2011) realized that one reason for the importance of oil is its perceived predictive power for US real GDP. They showed that there are only small gains in using the price of oil in forecasting cumulative real GDP growth from VAR models and is useful in finding out whether the price of oil is specified in nominal or in real terms and whether it is treated as exogenous or endogenous. Alquist et al. (2011) also state that linear autoregressive models fail to predict major economic downturns. They claimed that a possible explanation of this forecast failure is that the predictive relationship is nonlinear, so they tested multiple nonlinear joint forecasting models and found that they did not substantially improve forecast accuracy for the real GDP growth. They also found that one should be skeptical of the forecasting success of the nonlinear models during the 2008-2009 financial crisis, as the results suggested that the crisis did not help with the economic decline, which is highly improbable. Lastly, they proved that using structural forecasting models for the real price of oil would provide no insight into what drives the forecast and would not permit the policymaker to explore alternative hypothetical forecasting scenarios, which the VAR models provide.

Other researchers like Kulkarni and Haidar (2009) wanted to find the crude oil spot price in the shortterm, three days ahead using the optimal ANN model to reduce the negative impact of the price fluctuations. They used previous research from Moshiri and Foroutan (2005) to rule out the usage of ARMA and GARCH models. Another option they considered was a combination model that includes ANN, ARIMA, and Web mining proposed by Wang et al (2005). They realized that this model would not work because it depended on the knowledge base of human experts, inducing heavy unreliability in the model. Additionally, neither the rules nor the knowledge base were made public. Kulkarni and Haidar (2009) found that applying 3 days simple moving average to the original data, then transforming it into relative change is the best method among the others tested.

Forecasting Brent oil price

Manescu and Van Robays (2014) wanted to forecast the prices of Brent oil rather than the prices of crude oil as they believed that Brent oil pricing is the current benchmark and is monitored more by central banks than crude prices. Along with that, they wished to find the sensitivity of the forecast accuracies. They did so by assessing the forecasting performance of nine different methods and documented the important timevariation in each performance. Lastly, they proposed the ideal forecast combination for Brent oil pricing, which was a four model combination of the futures, the risk-adjusted futures, a Bayesian VAR model and a DGSE model of the oil market. They also found that none of the individual forecasting methods could consistently predict the Brent oil prices better than the futures or random-walk methods over time or forecast horizons. Using this information, the authors were able to form a forecast combination that is more accurate across horizons and more robust. Their four model combination performed better that the futures, the random walk, and the other individual models up to 11 quarters ahead and would produce a forecast whose performance was remarkably robust over time.

Beckers and Beidas-Strom (2015) decided in their paper to forecast the nominal price of oil rather than the real price due to the direct interest to the IMF forecasts. Forecasters have since used futures to predict the price of oil, but with the recent VAR models, practitioners have alternate methods for forecasting in short to medium terms. As a result, their paper wanted to find the ideal VAR model for the purpose of oil prediction. The results they obtained showed that in the short-term (1-12 months), the VAR models performed far better than the futures and random-walk models, but in the medium term (12-24 months), the futures model outperformed all the other models. During the short term, the futures model performed far worse than all other models because its high bias led to severe underprediction of its forecast. Over the full sample, the VAR models suffered from instability of small alterations to the specifications, subsamples, and lag lengths. The performance of the various models was dependent on the time period. The random walk worked better at stable prices, while the VAR performed better after the stock market collapse of 2008. Because of all these differences, Becker and Beidas-Strom (2015) concluded that forecasting the prices over a long sample is very difficult to do. 
Recent research

More recently, Dritsaki (2018) found that a certain configuration of a hybrid ARIMA-GARCH model was the most suitable for forecasting the returns of oil prices over a short term. He had decided on a hybrid model as he had noticed that the models individually could not handle the nonlinearity and volatility of the data. Since the ARIMA model was a robust linear model and the nonlinear GARCH model was powerful at handling volatility and risk return of oil price, he found that combining them created an accurate shortterm oil price forecasting model.

Funk (2018) tested many forecasting models and combinations of models to determine what combination of individual models is beneficial for the forecasting performance. He used the no-change benchmark (denoted RW in his paper), AR and ARMA models (AR and ARMA), the Futures model (Futures), forecasts based on crude oil inventories (Inventories OECD), a VAR model of the global oil market (VAR CLI), and a non-oil industrial raw materials real-time forecast (CRB Index), and watched price movements with oil sensitive stocks (Oil Stock). In all, he found that individually, the Futures model had the most gains in lowering the MSPE ratio and was substantially better than the no-change benchmark. However, he found that a combination consisting of four models, Futures, Inventories OECD, VAR CLI, and CRB Index showed lower MSPE ratios than the best individual models and therefore concluded that the combination would be the most reliable in forecasting crude oil prices.

An et al. (2019) used a machine learning approach to predict oil price. Their results stated that the price of oil was most affected by the US Federal Reserve rates and the US dollar index, and that factors such as instability in the Middle East had little to no effect on the prices of oil through their machine learning-based model. Al-Fattah (2019) used a hybrid approach of artificial intelligence with a genetic algorithm (GA), artificial neural network (ANN), and a datamining time series (DMTS) to construct a GANNATS model to forecast the prices of West Texas Intermediate crude oil. He found that his model closely matched the historical data of WTI futures price volatility and demonstrated capability in predicting the direction of crude oil price movements.

\section{The examination of TCU rule}

Published by Stanford University in 1992, International Oil Supplies and Demand-Energy Modeling Forum (1992) researched eleven popular oil price forecast models. Among these, nine use the TUC rule combined with the recursive simulation method to forecast oil price. It is clear that the TCU rule has become the standard in forecasting oil price.

The economic meaning of TCU rule

The concept of the TCU rule came from Forchheimer's dominant-firm model in oligopoly theory.

In this model, OPEC is the core firm and plays the role of price leader. Other non-OPEC entities are small players and they compete with each other. They cannot decide the market price by themselves and hence, follow the price set by the core firm. After their supply is subtracted from total demand, the residual demand can be estimated. The core firm will then use the residual demand to set the market price based on maximizing profit.

This static model does not match the response of the dynamic market place (Cartlon and Perloff 1990 and Scherer and Ross 1990). In reality, the market condition varies every minute. It is difficult for OPEC to estimate its revenue and cost at earlier stages. Instead of setting a price that will maximize their profit at earlier stages, setting an acceptable price dynamically is a better way to represent OPEC's behavior, Tussing and Harris (1992). As the change in price will alter current and future world demand and nonOPEC's supply, the TCU rule should be used with a recursive simulation model to forecast the oil price.

Application of the TCU rule

The world demand for crude oil depends heavily on OPEC which has a cost advantage in oil production, and thus OPEC has the ability to control the world's oil price Adelman (1990, 1993). Based on this phenomenon, the idea behind the TCU rule is as follows. If world demand for crude oil increases, forcing OPEC's capacity to approach its limit, OPEC will have a stronger influence over the oil price and thus will raise it. In contrast, if the world demand decreases, the price will drop. In other words, OPEC's capacity utilization rate can be viewed as an indicator 
of the change in world oil price. This idea can be converted to the equation:

$$
\Delta P / P=\alpha+\beta(1 /(1-\mathrm{UT}))
$$

where $\Delta P / P$ is the percentage change of price, UT is the capacity utilization rate, and $\alpha$ and $\beta$ are regression coefficients. This equation is the so-called price reaction function. The capacity utilization rate (UT) can be computed by dividing demand on OPEC's production by OPEC's capacity.

And the demand on OPEC's production $\left(D^{\mathrm{OPEC}}\right)$ can be computed by subtracting non-OPEC's supply $\left(S^{\text {non-OPEC }}\right)$ from world demand $\left(D^{\text {world }}\right)$, as shown through those two equations;

$D^{\mathrm{OPEC}}=D^{\text {world }}-S^{\text {non-OPEC }}$

and

$\mathrm{UT}=D^{\mathrm{OPEC}} /$ Capacity

Figure 1 illustrates the process of forecasting oil price using the TCU recursive simulation model.

In general, the price in the previous period is set as the initial price (PR). For world demand and nonOPEC's supply, there are different ways to compute these in different models. After world demand and non-OPEC's supply are known, the OPEC's capacity utilization rate, the percentage change of price and, thus, the current oil price (PS) can be calculated. If PS is not equal to PR, then PR will be set to PS and the whole process is repeated until PS is equal to PR. This PS is the final prediction of current oil price.

\section{The examination of the price reaction function}

The price reaction function implies that when the capacity utilization rate approaches one, the oil price will approach infinity. This phenomenon does not coincide with reality. During the simulation, if the price is so low that the demand on OPEC's production is over the capacity, the oil price will start to decrease. This is another unreasonable phenomenon. In addition to the unreasonable outcomes, there are some disadvantages of using capacity utilization rate. First, the estimate of capacity is not so easy because it involves the various issues of technology, geology, market price, and cost. Moreover, the exact volume of capacity is confidential and hence general researchers cannot gather this information easily. And usually, the producers adjust its capacity according to market demand and supply. However, in the TCU recursive simulation model, the capacity is viewed as a parameter, which does not relate to market demand and supply.

The revision of price reaction function

Because of all the reasons mentioned before, some revisions of the price reaction function will be made. As shown in Eq. 3, the capacity utilization rate can be computed by dividing demand on OPEC's production by capacity. Moreover, OPEC will adjust its capacity according to previous and current market demand. Thus, the demand on OPEC's production in the current and previous periods must play an important role in the determination of oil price. Replacing capacity utilization rate by demand on OPEC's production has some advantages; Compared to the estimate of capacity, the estimate of demand on OPEC's production is relatively simple. As shown in Eq. 2, the demand on OPEC's production can be computed by subtracting non-OPEC production from world demand. Also using demand on OPEC's production in the price reaction function can solve the problem of viewing capacity as a parameter. To replace the capacity utilization rate, the original price reaction function will be revised into the following equation.

$\Delta P / P_{t-1}=\alpha+\beta 1\left(D_{t-1}^{\mathrm{OPEC}}\right)+\beta 2\left(D_{t}^{\mathrm{OPEC}}\right)$

where $D_{t-1}^{\mathrm{OPEC}}$ is last period's demand on OPEC's production, $D_{t}^{\mathrm{OPEC}}$ is current period's demand on OPEC's production, and $\alpha, \beta 1$, and $\beta 2$ are regression coefficients. Using historical data ${ }^{2}$ from year 1987 to 2017, the regression coefficients can be calculated. The regression results are shown in Table 1.

As one can see in Table 1, the explanatory power of predictors is only $5.65 \%$.

Hence, more revisions need be made. In Eq. $4, \Delta P /$ $P_{t-1}$ can be decomposed into $\left(P_{t}-P_{t-1}\right) / P_{t-1}$. If $P_{t-1}$ is moved from the left side of the equation to the right side, viewing $P_{t-1}$ as another predictor variable, the new equation can be re-written as

\footnotetext{
${ }^{2}$ The average F.O.B. cost of crude oil from all OPEC countries is used as the crude oil price. All prices have been adjusted to US dollars.
} 
Fig. 1 Flowchart of TCU recursive simulation model

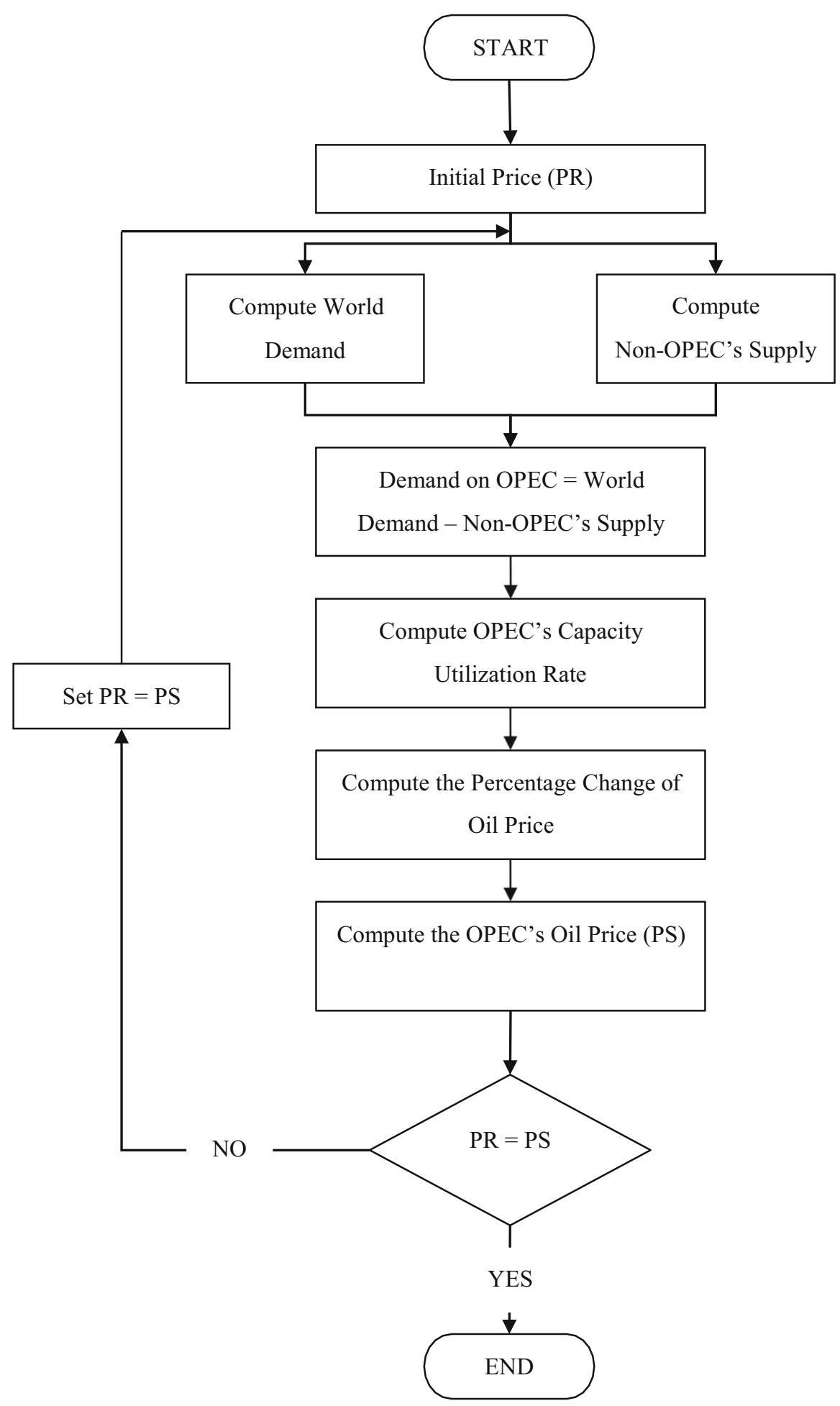


Table 1 Summary of regression result-Eq. 4 (1987-2017)

\begin{tabular}{ll}
\hline Predictor & Coefficients \\
\hline Intercept & 0.017801673 \\
Demand OPEC $(t)$ & $5.3124 \mathrm{E}-05$ \\
Demand OPEC $(t-1)$ & $-5.2402 \mathrm{E}-05$ \\
R-squared & 0.056480549 \\
\hline
\end{tabular}

Table 2 Summary of regression result—Eq. 5 (1987-2017)

\begin{tabular}{lr}
\hline Predictor & \multicolumn{1}{c}{ Coefficients } \\
\hline Intercept & -22.00949477 \\
Demand OPEC $(t)$ & 0.002908871 \\
Demand OPEC $(t-1)$ & 0.001796465 \\
Price $(t-1)$ & 0.763724436 \\
R-squared & 0.817352292 \\
\hline
\end{tabular}

$P_{t}=\alpha+\beta 1\left(P_{t-1}\right)+\beta 2\left(D_{t-1}^{\mathrm{OPEC}}\right)+\beta 3\left(D_{t}^{\mathrm{OPEC}}\right)$.

The regression result is summarized in Table 2. As one can see, the explanatory power dramatically increased from 5.65 to $81.74 \%$. This may be caused by some unusual observations.

After historical data have been reviewed, three unusual observations were found. In 1990, there was a spike in the price of crude oil due to the uncertainty associated with Iraq's invasion of Kuwait and the resulting Gulf War. Recession in 2008, and again recession at a smaller scale in 2015 contributed to uncertainty in crude oil prices.

The increase or decrease of crude oil price in these years is caused by many factors other than price, demand, and supply. Because these factors are not included in Eq. 5 as explanatory variables, the data in these years should be excluded. The regression result excluding data in 1990, 2008, and 2015 is shown as follows: As you can see in Table 3, the explanatory power increased from 81.74 to $90.19 \%$. This result is quite acceptable. Therefore, Eq. 5 will be used as the new price reaction function. This equation, combined with coefficients in Table 3 , will then be used in our crude oil price forecast model.

\section{The crude oil price forecast model}

In the previous section, the TCU rule has been examined and revisions of the price reaction function have been made. To forecast the crude oil price, two more equations are required. One is to calculate the world demand, and the other is to calculate the nonOPEC's supply.

World demand function

Equation 5 was obtained through a process of trial and error. In this process, all possible predictor variables and their transformation forms ${ }^{3}$ were first put together. Then, all possible combinations of these variables were used in multiple regression analysis and their explanatory powers were recorded. Finally, the combination with the highest explanatory power was selected. The process may not be mathematically justified. The composition of Eq. 5 may lack appropriate explanation and support from economic theory. However, as mentioned earlier, the purpose of the TCU recursive simulation model is to predict human behavior. Therefore, as long as the behavior pattern can be captured and the observed variables can be quantified, this process can be regarded as a method to predict oil price.

To obtain the world demand function, the same process is used. Using historical data from years 1987 through 2017, excluding unusual observations, ${ }^{4}$ the regression result is summarized in Table 4 , and the world demand function can be written as

$D_{t}^{\text {world }}=\alpha+\beta 1\left(P_{t}\right)+\beta 2\left(1 / P_{t}\right)+\beta 3 \ln \left(D_{t-1}^{\text {world }}\right)$

where $P_{t}$ is current oil price, $D_{t}^{\text {world }}$ is current world demand, and $D_{t-1}^{\text {world }}$ is world demand in previous period.

\footnotetext{
${ }^{3}$ When there is a nonlinear relationship between dependent and independent variables, the transformation of independent variable can be employed so that the resulting relationship with the dependent variable is linear. Four of the most common transformations used to generate new independent variables are the reciprocal, the log, the square root and the square.

4 As mentioned earlier, the increase or decrease of crude oil price in years 1990, 2008, and 2015 is caused by factors that are not used as predictor variables in the multiple regression model. Therefore, these unusual observations should be excluded from the multiple regression analysis.
} 
Table 3 Summary of regression result-Eq. 5 (excluding unusual observations) Years: 1990, 2008, 2015

\begin{tabular}{lr}
\hline Predictor & \multicolumn{1}{c}{ Coefficients } \\
\hline Intercept & -21.6609319 \\
Demand OPEC $(t)$ & 0.003532678 \\
Demand OPEC $(t-1)$ & 0.002558957 \\
Price $(t-1)$ & 0.853754153 \\
R-squared & 0.901956471 \\
\hline
\end{tabular}

Table 4 Summary of regression result-Eq. 6 (1987-2017)

\begin{tabular}{ll}
\hline Predictor & Coefficients \\
\hline Intercept & $-657,562.0139$ \\
Price $(t)$ & -1.657597015 \\
Ln demand $(t-1)$ & $65,358.55041$ \\
$1 / P(t)$ & $-13,351.50338$ \\
R-squared & 0.975315889 \\
\hline
\end{tabular}

As one can see in Table 4, the explanatory power is 97.35\%. The result is thus acceptable. Thus, Eq. 6 will be used as world demand function in the forecast model.

Non-OPEC's supply function

To obtain non-OPEC's supply function, the same process and data set is used. The summary of regression result is presented in Table 5, and nonOPEC's supply function can be written as

$S_{t}^{\text {non }-\mathrm{OPEC}}=\alpha+\beta 1\left(P_{t}\right)+\beta 2\left(S_{t-1}^{\mathrm{non}-\mathrm{OPEC}}\right)$

where $S_{t}^{\text {non-OPEC }}$ is current non-OPEC's supply and $S_{t-1}^{\text {non-OPEC }}$ is the supply in the last period.

The predictor variables explained most the variation of dependent variable, non-OPEC's supply. Thus, there should be no hesitation to use Eq. 7 as the nonOPEC's supply function in the forecast model.

\section{Basic assumptions}

Before the forecast process starts, some basic assumptions need to be reviewed. Firstly, the crude oil price is
Table 5 Summary of regression result-Eq. 7 (1987-2017)

\begin{tabular}{lc}
\hline Predictor & Coefficients \\
\hline Intercept & 70.66790116 \\
Non-OPEC production $(t-1)$ & 0.99793886 \\
Price $(t)$ & 5.51108737 \\
R-squared & 0.950371597 \\
\hline
\end{tabular}

heavily influenced by OPEC. According to Forchheimer's dominant-firm model, because of OPEC's production advantage, OPEC has the power to decide the crude oil price; non-OPEC can only follow the price set by OPEC. Secondly, the indicators of crude oil price should be considered.

OPEC should play the role of price leader. As discussed in previous sections, current demand on OPEC's production, last period's demand on OPEC's production, and last period's crude oil price should be the only indicators of crude oil price. Also, markets can respond fully and immediately. Because the forecast model is a dynamic system simulation model, it must be assumed that once a price is given, the market demand and supply can be determined immediately. Before the market achieves equilibrium, excess demand caused by price that is too low or excess supply caused by price that is too high will keep supplier and consumer adjusting their production and consumption behaviors until the market achieves equilibrium.

Forecasting annual crude oil price

In this section, Eqs. 5, 6, and 7 are used in the forecast model to predict crude oil price. We illustrate the model in Fig. 2. We experimented with four different methods (Method 1, Method 2, Method 3 and a Combination Method). The flowchart below demonstrates our methodology of using the coefficients and equations to calculate the forecasted price for the next year. However, the equations and steps to derive the forecasted value are the same for all methods.

An example to forecast crude oil price in year 2017 in Microsoft Excel is presented following the discussion of the flowchart in Fig. 2.

In all tables where forecasts were presented using the above methods (Method 1, Method 2, Method 3 
and a Combination Method), the notation "DNE" refers to "Does not Exist."

As the forecast is reported only from 1991 to 2017 in our analysis, we report forecasts from 1986 to 1990 as DNE.

The following is an example of using Microsoft Excel to forecast the crude oil price in 2017 with the coefficients from Method 1. All calculations for forecast are the same with every method, and it is simply that the process of deriving the coefficients of the equation is different for each method and will lead to different coefficients:

Step 1 Enter the predictor variables of the previous period. Since we are forecasting the price of crude oil for 2017, the previous period would be 2016. As a result, the predictor values would be the price (43.1451923959272), world demand (80,841.606), the Non-OPEC Production $(45,226.765)$, and demand OPEC $(35,614.841)$.

Step 2 Set the initial price PR to the actual price of the previous period, in this case 2016. As a result, $\mathrm{PR}=43.1451923959272$.

Step 3 Using Eq. 6, calculate the World Demand of crude oil using the actual world demand of the previous 2016 period. As a result, the forecasted World Demand of 2017 should be $80,624.77925=-657,562.013925192+$ $(-1.65759701517087 *$ $43.1451923959272)+(65,358.5504135525$ $* \ln (80,841.606)+(-13,351.5033831124$ * 1/43.1451923959272).

Step 4 Using Eq. 7, calculate the non-OPEC's supply using non-OPEC's supply from the previous 2016 period. As a result, the forecasted non-OPEC's supply of 2017 should be 45,441.99115 = $70.66790116+(0.99793886 *$ $45,226.77)+(5.51108737 *$ 43.1451923959272).

Step 5 Using the results from Steps 3 and 4 as well as Eq. 2, calculate the demand of OPEC production. As a result, the demand for OPEC production in 2017 should be $35,182.79=80,624.77925-45,441.99115$.
Step 6 Using the demand for OPEC production from Step 5, the demand for OPEC production from the previous period, $\mathrm{PR}$, and Eq. 5, we can calculate the PS, or the current crude oil price. As a result, PS should be $48.32707271=$ $-21.6609319036754+$ $(0.00353267816445286 * 35,182.79)+$ $(-0.0025589570889436 *$ $35,614.841)+(0.853754152644323 *$ 43.1451923959272).

Step 7 As we can see, PR $=43.1451923959272$ and PS $=48.32707271$. Since PR does not equal PS, PR will be set to PS, so $\mathrm{PR}=48.32707271$, and the steps will be run through repeatedly until PR $=$ PS. In the end, with the coefficients from Method 1 , the final PS of 2017 is 76.1074395660732. So, the forecasted crude oil price of 2017 is 76.1074395660732 .

Method 1

We ran a regression on all the data from 1987 to 2017 in order to come up with the coefficients for each of these equations. As a result, the coefficients that are in the tables are the only set of coefficients used for the forecasting.

$\Delta P / P_{t-1}=\alpha+\beta 1\left(D_{t-1}^{\mathrm{OPEC}}\right)+\beta 2\left(D_{t}^{\mathrm{OPEC}}\right)$

See Table 1.

$P_{t}=\alpha+\beta 1\left(P_{t-1}\right)+\beta 2\left(D_{t-1}^{\mathrm{OPEC}}\right)+\beta 3\left(D_{t}^{\mathrm{OPEC}}\right)$.

See Tables 2 and 3.

$D_{t}^{\text {world }}=\alpha+\beta 1\left(P_{t}\right)+\beta 2\left(1 / P_{t}\right)+\beta 3 \ln \left(D_{t-1}^{\text {world }}\right)$

(6)

See Table 4.

$S_{t}^{\text {non-OPEC }}=\alpha+\beta 1\left(P_{t}\right)+\beta 2\left(S_{t-1}^{\text {non-OPEC }}\right)$

See Table 5.

The forecasted values obtained using Method 1 are given in the below table. As stated earlier, DNE refers to "Does not Exist." 
Fig. 2 Flowchart of annual crude oil price forecast model

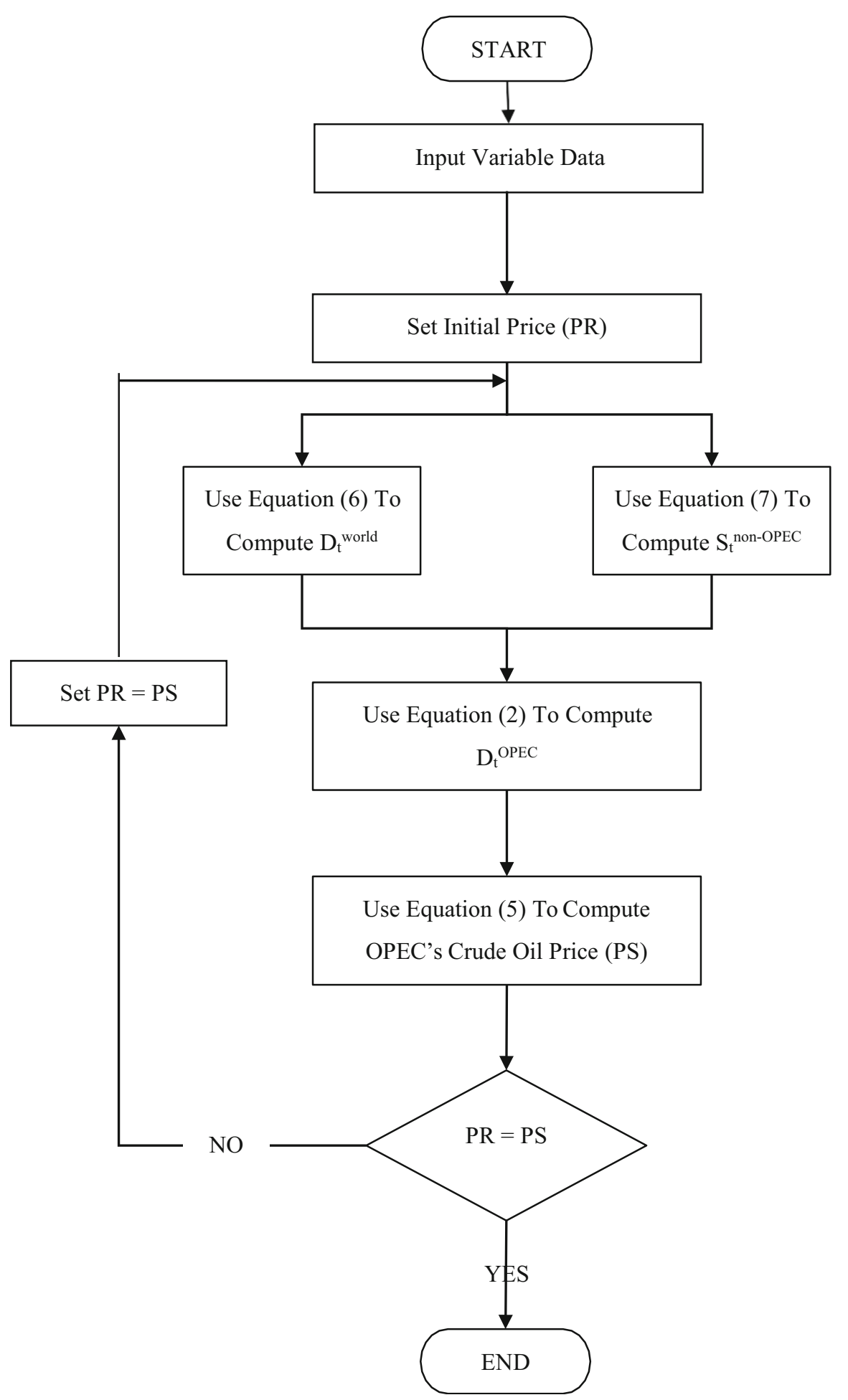




\begin{tabular}{|c|c|c|c|c|c|}
\hline Year & Actual & $\begin{array}{l}\text { World } \\
\text { demand }\end{array}$ & $\begin{array}{l}\text { Non- } \\
\text { OPEC } \\
\text { production }\end{array}$ & $\begin{array}{l}\text { Demand } \\
\text { OPEC }\end{array}$ & $\begin{array}{l}\text { Forecasted } \\
\text { price }\end{array}$ \\
\hline 1986 & 15.03 & $56,325.61$ & $38,453.61$ & 17,872 & DNE \\
\hline 1987 & 19.17 & $56,650.07$ & $38,640.75$ & $18,009.32$ & DNE \\
\hline 1988 & 15.98 & $58,696.86$ & $38,652.86$ & 20,044 & DNE \\
\hline 1989 & 19.64 & $59,801.83$ & $38,023.25$ & $21,778.59$ & DNE \\
\hline 1990 & 24.47 & $60,496.75$ & $37,563.68$ & $22,933.07$ & DNE \\
\hline 1991 & 21.50 & $60,127.63$ & $37,255.58$ & $22,872.05$ & 25.34403 \\
\hline 1992 & 20.56 & $60,100.2$ & $35,897.92$ & $24,202.28$ & 23.49511 \\
\hline 1993 & 18.45 & $60,172.95$ & $35,210.09$ & $24,962.86$ & 34.72071 \\
\hline 1994 & 17.19 & $61,173.47$ & $35,783.9$ & $25,389.57$ & 40.22087 \\
\hline 1995 & 18.44 & $62,433.68$ & $36,376.1$ & $26,057.58$ & 44.98176 \\
\hline 1996 & 22.11 & $63,818.23$ & $37,228.31$ & $26,589.92$ & 51.01424 \\
\hline 1997 & 20.61 & $65,805.95$ & $37,856.04$ & $27,949.92$ & 55.51825 \\
\hline 1998 & 14.45 & $67,031.77$ & $37,985.36$ & $29,046.41$ & 64.28711 \\
\hline 1999 & 19.26 & $65,967.39$ & $38,064.91$ & $27,902.49$ & 70.48958 \\
\hline 2000 & 30.30 & $68,526.65$ & $38,820.06$ & $29,706.59$ & 63.97958 \\
\hline 2001 & 25.95 & $68,131.91$ & $39,296.32$ & $28,835.6$ & 73.32451 \\
\hline 2002 & 26.11 & $67,290.17$ & $40,112.02$ & $27,178.15$ & 68.49023 \\
\hline 2003 & 31.12 & $69,460.24$ & $40,788.42$ & $28,671.83$ & 59.08099 \\
\hline 2004 & 41.44 & $72,595.18$ & $41,323.25$ & $31,271.93$ & 66.11404 \\
\hline 2005 & 56.49 & $73,869.21$ & $41,096.58$ & $32,772.63$ & 76.30616 \\
\hline 2006 & 66.02 & $73,621.39$ & $41,138.02$ & $32,483.37$ & 82.25424 \\
\hline 2007 & 72.32 & $73,330.83$ & $41,094.98$ & $32,235.84$ & 81.14913 \\
\hline 2008 & 99.57 & $74,301.01$ & $40,578.15$ & $33,722.85$ & 80.37065 \\
\hline 2009 & 61.65 & $73,120.57$ & $41,053.98$ & $32,066.59$ & 86.75108 \\
\hline 2010 & 79.40 & $74,887.25$ & $41,839.47$ & $33,047.78$ & 79.8512 \\
\hline 2011 & 94.88 & $74,908.39$ & $41,779.05$ & $33,129.34$ & 81.26497 \\
\hline 2012 & 94.11 & $76,367.46$ & $42,023.42$ & $34,344.04$ & 81.68731 \\
\hline 2013 & 97.91 & $76,448.82$ & $43,154.69$ & $33,294.13$ & 84.62633 \\
\hline 2014 & 93.26 & $78,361.77$ & $45,021.37$ & $33,340.39$ & 78.20684 \\
\hline 2015 & 48.69 & $80,755.05$ & $46,186.55$ & $34,568.5$ & 72.12382 \\
\hline 2016 & 43.15 & $80,841.61$ & $45,226.77$ & $35,614.84$ & 70.24915 \\
\hline 2017 & 50.88 & & & $35,467.53$ & 76.10744 \\
\hline
\end{tabular}

\section{Method 2}

We ran a regression on all the data from 1986 to 1990 to get the coefficients for Eqs. 5, 6, and 7 mentioned in the example forecast with Method 1 for 1991. From there, we incremented the year by one and added the previous year's data to the data that was used in the regression. For example, the coefficients for 1992 
were from a regression of the data from 1986, 1987, 1988, 1989, 1990, and 1991. The coefficients for 2017 were from a regression of the data from 1986 to 2016. When forecasting the price of crude oil for a certain year with Method 2, the coefficients used were the coefficients that were associated with the previous year. For example, forecasting the price of crude oil for year 1992 will use the coefficients for 1991 .

$$
P_{t}=\alpha+\beta 1\left(P_{t-1}\right)+\beta 2\left(D_{t-1}^{\mathrm{OPEC}}\right)+\beta 3\left(D_{t}^{\mathrm{OPEC}}\right) .
$$

\begin{tabular}{lcllll}
\hline Year & Intercept & Demand OPEC $(t)$ & Demand OPEC $(t-1)$ & Price $(t-1)$ & R-squared \\
\hline 1991 & 5.198102 & -0.00098 & 0.002069 & -0.35896 & 1 \\
1992 & 6.677646 & -0.00107 & 0.002066 & -0.339 & 0.991835 \\
1993 & 14.40669 & -0.00107 & 0.001382 & -0.03405 & 0.493459 \\
1994 & 17.40085 & -0.0009 & 0.0008 & 0.235676 & 0.284812 \\
1995 & 17.30478 & -0.0009 & 0.00081 & 0.225707 & 0.290868 \\
1996 & 15.23411 & -0.00089 & 0.000987 & 0.137695 & 0.246331 \\
1997 & 13.78803 & -0.00072 & 0.000859 & 0.159763 & 0.266174 \\
1998 & 18.96838 & -0.00121 & 0.001094 & 0.196801 & 0.153403 \\
1999 & 18.80984 & -0.00114 & 0.001008 & 0.215022 & 0.153484 \\
2000 & 10.84204 & 0.001014 & -0.00067 & -0.00674 & 0.118157 \\
2001 & 6.458585 & 0.000427 & $-8.3 \mathrm{E}-05$ & 0.256301 & 0.210529 \\
2002 & 6.250947 & $-1.9 \mathrm{E}-05$ & 0.000349 & 0.307606 & 0.278247 \\
2003 & 0.90667 & 0.000658 & -0.00024 & 0.46844 & 0.362239 \\
2004 & -7.8645 & 0.001817 & -0.00128 & 0.727879 & 0.587846 \\
2005 & -14.3536 & 0.001984 & -0.00149 & 1.097245 & 0.780625 \\
2006 & -14.4942 & 0.001873 & -0.00141 & 1.151682 & 0.884085 \\
2007 & -14.7638 & 0.001959 & -0.00145 & 1.099958 & 0.925201 \\
2008 & -14.7638 & 0.001959 & -0.00145 & 1.099958 & 0.925201 \\
2009 & -24.9569 & 0.003311 & -0.00201 & 0.637088 & 0.825986 \\
2010 & -29.6232 & 0.004208 & -0.00279 & 0.702558 & 0.834277 \\
2011 & 16.00549 & 0.001968 & 0.001964 & 0.133701 & 0.854656 \\
2012 & -30.4922 & 0.004448 & -0.00308 & 0.792459 & 0.88501 \\
2013 & -29.6161 & 0.004114 & -0.00281 & 0.830278 & 0.900323 \\
2014 & -29.8075 & 0.004099 & -0.00278 & 0.823033 & 0.912469 \\
2015 & -29.8075 & 0.004099 & -0.00278 & 0.823033 & 0.912469 \\
2016 & -20.7537 & 0.003546 & -0.00262 & 0.859233 & 0.901773 \\
\hline & & & & &
\end{tabular}


$D_{t}^{\text {world }}=\alpha+\beta 1\left(P_{t}\right)+\beta 2\left(1 / P_{t}\right)+\beta 3 \ln \left(D_{t-1}^{\text {world }}\right)$

\begin{tabular}{llclll}
\hline Year & Intercept & Price $(t)$ & Ln demand $(t-1)$ & $1 / P(t)$ & R-squared \\
\hline 1991 & $-590,794$ & 958.6609 & $55,440.24$ & $438,617.3$ & 0.914016 \\
1992 & $-570,686$ & 1019.849 & $53,408.99$ & $456,913.5$ & 0.917362 \\
1993 & $-529,888$ & 1068.156 & $49,587.72$ & 459,771 & 0.913784 \\
1994 & $-550,451$ & 1094.031 & $51,330.45$ & $477,943.4$ & 0.928264 \\
1995 & $-613,039$ & 996.1872 & $57,308.24$ & $457,147.6$ & 0.916873 \\
1996 & $-685,904$ & 1091.293 & $63,642.25$ & $486,003.6$ & 0.914104 \\
1997 & $-766,919$ & 1016.363 & $71,238.52$ & $467,800.1$ & 0.929635 \\
1998 & $-637,854$ & 150.3882 & $62,820.44$ & $89,563.87$ & 0.939271 \\
1999 & $-582,852$ & 517.1611 & $56,537.73$ & 222,145 & 0.934024 \\
2000 & $-590,117$ & 706.3997 & $56,569.36$ & $284,178.2$ & 0.951216 \\
2001 & $-571,105$ & 722.1395 & $54,754.36$ & 296,557 & 0.956574 \\
2002 & $-554,407$ & 728.4099 & $53,183.34$ & $305,333.1$ & 0.955725 \\
2003 & $-554,251$ & 747.9182 & $53,101.28$ & $312,347.3$ & 0.962784 \\
2004 & $-567,345$ & 418.9849 & $55,511.97$ & 178,630 & 0.965195 \\
2005 & $-584,512$ & 114.9131 & $58,289.29$ & $36,462.21$ & 0.954165 \\
2006 & $-592,837$ & 24.78802 & $59,431.34$ & $-11,064.3$ & 0.953217 \\
2007 & $-598,510$ & -2.91539 & $60,068.63$ & $-26,510.3$ & 0.956858 \\
2008 & $-595,893$ & 3.776775 & $59,798.13$ & $-22,004.6$ & 0.961927 \\
2009 & $-586,095$ & 4.658961 & $58,894.43$ & $-19,031.6$ & 0.961946 \\
2010 & $-583,607$ & 11.34089 & $58,644.43$ & $-16,427$ & 0.964079 \\
2011 & $-583,949$ & 6.675203 & $58,702.08$ & $-20,300.5$ & 0.966742 \\
2012 & $55,983.49$ & 21.19092 & 5002.125 & $35,527.19$ & 0.96904 \\
2013 & $-582,975$ & 11.1244 & $58,590.24$ & $-17,008.3$ & 0.971515 \\
2014 & $-588,110$ & 16.86857 & $59,015.24$ & $-10,626.8$ & 0.972326 \\
2015 & $-641,470$ & 1.905646 & $63,896.4$ & $-14,044.8$ & 0.969978 \\
2016 & $-651,193$ & -0.28337 & $64,779.66$ & $-13,553.1$ & 0.972959 \\
\hline & & & & &
\end{tabular}


$S_{t}^{\text {non-OPEC }}=\alpha+\beta 1\left(P_{t}\right)+\beta 2\left(S_{t-1}^{\text {non }-\mathrm{OPEC}}\right)$

(7)

\begin{tabular}{|c|c|c|c|c|}
\hline Year & Intercept & Non-OPEC production $(t-1)$ & Price $(t)$ & R-squared \\
\hline 1991 & $10,030.07$ & 0.774753 & -81.8824 & 0.816474 \\
\hline 1992 & $-23,743.3$ & 1.612909 & -1.65425 & 0.844339 \\
\hline 1993 & -9220.11 & 1.257628 & -48.9493 & 0.901768 \\
\hline 1994 & 2401.882 & 0.977552 & -96.5621 & 0.840716 \\
\hline 1995 & 5527.834 & 0.898684 & -101.697 & 0.813502 \\
\hline 1996 & 7745.215 & 0.810134 & -40.8787 & 0.726127 \\
\hline 1997 & 7659.028 & 0.808499 & -29.8292 & 0.696327 \\
\hline 1998 & 7586.125 & 0.815514 & -38.8999 & 0.709374 \\
\hline 1999 & 7210.478 & 0.826384 & -39.4444 & 0.718787 \\
\hline 2000 & 5209.664 & 0.844991 & 30.12606 & 0.713394 \\
\hline 2001 & 3988.66 & 0.873058 & 40.02221 & 0.751543 \\
\hline 2002 & 1995.388 & 0.921447 & 50.72065 & 0.793232 \\
\hline 2003 & 1430.173 & 0.933924 & 55.81661 & 0.844306 \\
\hline 2004 & 1768.546 & 0.931979 & 42.84179 & 0.87895 \\
\hline 2005 & 714.371 & 0.979264 & 8.783592 & 0.881328 \\
\hline 2006 & 201.2863 & 0.996499 & 2.521949 & 0.895189 \\
\hline 2007 & -137.934 & 1.00737 & -0.66393 & 0.905012 \\
\hline 2008 & -1286.83 & 1.041661 & -6.89937 & 0.908175 \\
\hline 2009 & -1414.98 & 1.04461 & -5.81319 & 0.912077 \\
\hline 2010 & -1092.66 & 1.034037 & -2.35854 & 0.915165 \\
\hline 2011 & -1164.04 & 1.036402 & -3.08264 & 0.922112 \\
\hline 2012 & -1100.49 & 1.034318 & -2.46776 & 0.928433 \\
\hline 2013 & -823.294 & 1.024907 & 0.601758 & 0.930688 \\
\hline 2014 & -2624.28 & 1.072095 & 0.779161 & 0.932088 \\
\hline 2015 & -4217.77 & 1.115893 & -1.82093 & 0.946349 \\
\hline 2016 & 318.654 & 0.991142 & 5.889455 & 0.943537 \\
\hline
\end{tabular}

The forecasted values obtained using Method 2 are given in the below table. As stated earlier, DNE refers to "Does not Exist."

\begin{tabular}{llllll}
\hline Year & Actual & World demand & Non-OPEC production & Demand OPEC & Forecasted price \\
\hline 1986 & 15.03 & $56,325.61$ & $38,453.61$ & 17,872 & DNE \\
1987 & 19.17 & $56,650.07$ & $38,640.75$ & $18,009.32$ & DNE \\
1988 & 15.98 & $58,696.86$ & $38,652.86$ & 20,044 & DNE \\
1989 & 19.64 & $59,801.83$ & $38,023.25$ & $21,778.59$ & DNE \\
1990 & 24.47 & $60,496.75$ & $37,563.68$ & $22,933.07$ & DNE \\
1991 & 21.50 & $60,127.63$ & $37,255.58$ & $22,872.05$ & DNE \\
1992 & 20.56 & $60,100.2$ & $35,897.92$ & $24,202.28$ & 21.94895 \\
1993 & 18.45 & $60,172.95$ & $35,210.09$ & $24,962.86$ & 21.54681 \\
1994 & 17.19 & $61,173.47$ & $35,783.9$ & $25,389.57$ & 20.28092 \\
\hline
\end{tabular}


continued

\begin{tabular}{|c|c|c|c|c|c|}
\hline Year & Actual & World demand & Non-OPEC production & Demand OPEC & Forecasted price \\
\hline 1995 & 18.44 & $62,433.68$ & $36,376.1$ & $26,057.58$ & 19.03475 \\
\hline 1996 & 22.11 & $63,818.23$ & $37,228.31$ & $26,589.92$ & 18.89789 \\
\hline 1997 & 20.61 & $65,805.95$ & $37,856.04$ & $27,949.92$ & 19.88638 \\
\hline 1998 & 14.45 & $67,031.77$ & $37,985.36$ & $29,046.41$ & 19.6061 \\
\hline 1999 & 19.26 & $65,967.39$ & $38,064.91$ & $27,902.49$ & 17.73101 \\
\hline 2000 & 30.30 & $68,526.65$ & $38,820.06$ & $29,706.59$ & 18.97899 \\
\hline 2001 & 25.95 & $68,131.91$ & $39,296.32$ & $28,835.6$ & 20.67131 \\
\hline 2002 & 26.11 & $67,290.17$ & $40,112.02$ & $27,178.15$ & 21.76323 \\
\hline 2003 & 31.12 & $69,460.24$ & $40,788.42$ & $28,671.83$ & 21.98432 \\
\hline 2004 & 41.44 & $72,595.18$ & $41,323.25$ & $31,271.93$ & 22.87479 \\
\hline 2005 & 56.49 & $73,869.21$ & $41,096.58$ & $32,772.63$ & Did not Converge \\
\hline 2006 & 66.02 & $73,621.39$ & $41,138.02$ & $32,483.37$ & Did not Converge \\
\hline 2007 & 72.32 & $73,330.83$ & $41,094.98$ & $32,235.84$ & Did not Converge \\
\hline 2008 & 99.57 & $74,301.01$ & $40,578.15$ & $33,722.85$ & Did not Converge \\
\hline 2009 & 61.65 & $73,120.57$ & $41,053.98$ & $32,066.59$ & Did not Converge \\
\hline 2010 & 79.40 & $74,887.25$ & $41,839.47$ & $33,047.78$ & 46.80165 \\
\hline 2011 & 94.88 & $74,908.39$ & $41,779.05$ & $33,129.34$ & 55.37141 \\
\hline 2012 & 94.11 & $76,367.46$ & $42,023.42$ & $34,344.04$ & 171.5954 \\
\hline 2013 & 97.91 & $76,448.82$ & $43,154.69$ & $33,294.13$ & 1704.521 \\
\hline 2014 & 93.26 & $78,361.77$ & $45,021.37$ & $33,340.39$ & 73.22561 \\
\hline 2015 & 48.69 & $80,755.05$ & $46,186.55$ & $34,568.5$ & 42.64115 \\
\hline 2016 & 43.15 & $80,841.61$ & $45,226.77$ & $35,614.84$ & 56.01625 \\
\hline 2017 & 50.88 & & & $35,467.53$ & 73.90768 \\
\hline
\end{tabular}

\section{Method 3}

We ran a regression on all the data from 1986 to 1990 to get the coefficients for Eqs. 5, 6, and 7 mentioned in the example forecast with Method 1 for 1991. From there, we incremented the year by one and ran a regression of the previous 5 years' data in order to get the coefficients for Eqs. 5, 6, and 7. For example, the coefficients for 1992 were from a regression of the data from 1987, 1988, 1989, 1990, and 1991. The coefficients for 2017 were from a regression of the data from 2012 to 2016. When forecasting the price of crude oil for a certain year with Method 3, the coefficients used are the coefficients that were associated with the previous year. For example, forecasting the price of crude oil for year 1992 would use the coefficients for 1991 .

$P_{t}=\alpha+\beta 1\left(P_{t-1}\right)+\beta 2\left(D_{t-1}^{\mathrm{OPEC}}\right)+\beta 3\left(D_{t}^{\mathrm{OPEC}}\right)$. 


\begin{tabular}{|c|c|c|c|c|c|}
\hline Year & Intercept & Demand OPEC $(t)$ & Demand OPEC $(t-1)$ & Price $(t-1)$ & R-squared \\
\hline 1991 & 5.198102 & -0.00098 & 0.002069 & -0.35896 & 1 \\
\hline 1992 & 6.677646 & -0.00107 & 0.002066 & -0.339 & 0.991835 \\
\hline 1993 & 14.40669 & -0.00107 & 0.001382 & -0.03405 & 0.493459 \\
\hline 1994 & 17.40085 & -0.0009 & 0.0008 & 0.235676 & 0.284812 \\
\hline 1995 & 17.30478 & -0.0009 & 0.00081 & 0.225707 & 0.290868 \\
\hline 1996 & 15.23411 & -0.00089 & 0.000987 & 0.137695 & 0.246331 \\
\hline 1997 & 13.78803 & -0.00072 & 0.000859 & 0.159763 & 0.266174 \\
\hline 1998 & 18.96838 & -0.00121 & 0.001094 & 0.196801 & 0.153403 \\
\hline 1999 & 18.80984 & -0.00114 & 0.001008 & 0.215022 & 0.153484 \\
\hline 2000 & 10.84204 & 0.001014 & -0.00067 & -0.00674 & 0.118157 \\
\hline 2001 & 6.458585 & 0.000427 & $-8.3 \mathrm{E}-05$ & 0.256301 & 0.210529 \\
\hline 2002 & 6.250947 & $-1.9 \mathrm{E}-05$ & 0.000349 & 0.307606 & 0.278247 \\
\hline 2003 & 0.90667 & 0.000658 & -0.00024 & 0.46844 & 0.362239 \\
\hline 2004 & -3.73584 & 0.003224 & -0.00254 & 0.488824 & 0.871768 \\
\hline 2005 & 58.81733 & 0.001254 & -0.00463 & 2.418189 & 0.938083 \\
\hline 2006 & -87.531 & 0.003058 & 0.000419 & 0.720866 & 0.997704 \\
\hline 2007 & -87.9475 & 0.002327 & 0.001291 & 0.651156 & 0.998461 \\
\hline 2008 & -87.9475 & 0.002327 & 0.001291 & 0.651156 & 0.998461 \\
\hline 2009 & -48.9632 & -0.00748 & 0.011858 & -0.4684 & 0.829242 \\
\hline 2010 & -755.646 & 0.019426 & 0.005797 & 0.044272 & 0.308865 \\
\hline 2011 & -710.137 & 0.025221 & -0.00156 & 0.196666 & 0.791732 \\
\hline 2012 & -2282.41 & 0.023753 & 0.053359 & -2.18053 & 0.999798 \\
\hline 2013 & -1022.47 & 0.017133 & 0.018577 & -0.91076 & 0.903998 \\
\hline 2014 & -124.216 & 0.000723 & 0.005362 & 0.164194 & 0.838836 \\
\hline 2015 & -124.216 & 0.000723 & 0.005362 & 0.164194 & 0.838836 \\
\hline 2016 & 477.2234 & -0.00932 & -0.00378 & 0.617744 & 0.958748 \\
\hline
\end{tabular}

$D_{t}^{\text {world }}=\alpha+\beta 1\left(P_{t}\right)+\beta 2\left(1 / P_{t}\right)+\beta 3 \ln \left(D_{t-1}^{\text {world }}\right)$

\begin{tabular}{lccccc}
\hline Year & Intercept & Price $(t)$ & Ln demand $(t-1)$ & $1 / P(t)$ & R-squared \\
\hline 1991 & $-590,794$ & 958.6609 & $55,440.24$ & $438,617.3$ & 0.914016 \\
1992 & $-570,686$ & 1019.849 & $53,408.99$ & $456,913.5$ & 0.917362 \\
1993 & $-529,888$ & 1068.156 & $49,587.72$ & 459,771 & 0.913784 \\
1994 & $-550,451$ & 1094.031 & $51,330.45$ & $477,943.4$ & 0.928264 \\
1995 & $-613,039$ & 996.1872 & $57,308.24$ & $457,147.6$ & 0.916873 \\
1996 & $-685,904$ & 1091.293 & $63,642.25$ & $486,003.6$ & 0.914104 \\
1997 & $-766,919$ & 1016.363 & $71,238.52$ & $467,800.1$ & 0.929635 \\
1998 & $-637,854$ & 150.3882 & $62,820.44$ & $89,563.87$ & 0.939271 \\
1999 & $-582,852$ & 517.1611 & $56,537.73$ & 222,145 & 0.934024 \\
2000 & $-590,117$ & 706.3997 & $56,569.36$ & $284,178.2$ & 0.951216 \\
\hline
\end{tabular}


continued

\begin{tabular}{|c|c|c|c|c|c|c|c|c|c|}
\hline Year & & Intercept & \multicolumn{2}{|c|}{ Price $(t)$} & \multicolumn{2}{|c|}{ Ln demand $(t-1)$} & \multicolumn{2}{|l|}{$1 / P(t)$} & R-squared \\
\hline 2001 & & $-571,105$ & \multicolumn{2}{|c|}{722.1395} & \multicolumn{2}{|c|}{$54,754.36$} & \multicolumn{2}{|c|}{296,557} & 0.956574 \\
\hline 2002 & & $-554,407$ & \multicolumn{2}{|c|}{728.4099} & \multicolumn{2}{|c|}{$53,183.34$} & \multicolumn{2}{|c|}{$305,333.1$} & 0.955725 \\
\hline 2003 & & $-554,251$ & \multicolumn{2}{|c|}{747.9182} & \multicolumn{2}{|c|}{$53,101.28$} & \multicolumn{2}{|c|}{$312,347.3$} & 0.962784 \\
\hline 2004 & & $-336,199$ & \multicolumn{2}{|c|}{-316.037} & \multicolumn{2}{|c|}{$39,221.21$} & \multicolumn{2}{|c|}{$-636,798$} & 0.983969 \\
\hline 2005 & & $-486,766$ & \multicolumn{2}{|c|}{-368.84} & \multicolumn{2}{|c|}{$53,027.92$} & \multicolumn{2}{|c|}{$-682,033$} & 0.992917 \\
\hline 2006 & & $-165,073$ & \multicolumn{2}{|c|}{-233.236} & \multicolumn{2}{|c|}{$23,466.51$} & \multicolumn{2}{|c|}{$-593,208$} & 0.999916 \\
\hline 2007 & & $117,991.3$ & \multicolumn{2}{|c|}{-188.907} & \multicolumn{2}{|c|}{-1969.9} & \multicolumn{2}{|c|}{$-646,010$} & 0.999809 \\
\hline 2008 & & $-82,217.7$ & \multicolumn{2}{|c|}{25.66934} & \multicolumn{2}{|c|}{$13,682.36$} & \multicolumn{2}{|c|}{$55,799.48$} & 0.713039 \\
\hline 2009 & & $344,405.5$ & \multicolumn{2}{|c|}{63.41434} & \multicolumn{2}{|c|}{$-24,917.8$} & \multicolumn{2}{|c|}{$270,532.4$} & 0.877985 \\
\hline 2010 & & $4,061,974$ & \multicolumn{2}{|c|}{430.4331} & \multicolumn{2}{|c|}{$-362,668$} & \multicolumn{2}{|c|}{$3,220,356$} & 0.9996 \\
\hline 2011 & & $-45,647.1$ & -130 & & 12,8 & 48.69 & $-1,07$ & ,619 & 0.704993 \\
\hline 2012 & & $-372,629$ & -333 & & 44,9 & 43.68 & $-2,32$ & ,615 & 0.823996 \\
\hline 2013 & & $-829,343$ & -657 & & 90,0 & 57.81 & $-4,13$ &, 712 & 0.882695 \\
\hline 2014 & & $-919,007$ & -1751 & & 114,8 & 07.2 & $-1.2 \mathrm{E}$ & +07 & 0.920274 \\
\hline 2015 & & $-1,067,208$ & -854 & & 112,7 & 26.7 & $-3,93$ &, 119 & 0.968909 \\
\hline 2016 & & $-767,692$ & -453 & & 80,8 & 56.82 & $-1,96$ & ,092 & 0.982085 \\
\hline$S_{t}^{\text {non- }-}$ & ${ }^{\mathrm{PEC}}=\alpha$ & $\chi+\beta 1\left(P_{t}\right)+\beta 2$ & non-OPEC $)$ & (7) & Year & Intercept & $\begin{array}{l}\text { Non-OPEC } \\
\text { production } \\
(t-1)\end{array}$ & Price $(t)$ & $\begin{array}{l}\text { R- } \\
\text { squared }\end{array}$ \\
\hline & & & & & 2012 & $-18,723.9$ & 1.535193 & -36.9795 & 0.768861 \\
\hline Year & Intercept & Non-OPEC & Price $(t)$ & & 2013 & 1562.389 & 0.974418 & 0.156847 & 0.626734 \\
\hline & & production & & squared & 2014 & $-35,175.8$ & 1.989812 & -60.6386 & 0.896525 \\
\hline & & $(t-1)$ & & & 2015 & $-64,124.5$ & 2.367465 & 75.9743 & 0.981528 \\
\hline 1991 & 10,030 & 0.774753 & -81.8824 & 0.816474 & 2016 & $-12,577.5$ & 1.238784 & 37.76309 & 0.711579 \\
\hline
\end{tabular}

The forecasted values obtained using Method 3 are given in the below table.

\begin{tabular}{rrrrl}
1992 & $-23,743.3$ & 1.612909 & -1.65425 & 0.844339 \\
1993 & -9220.11 & 1.257628 & -48.9493 & 0.901768 \\
1994 & 2401.882 & 0.977552 & -96.5621 & 0.840716 \\
1995 & 5527.834 & 0.898684 & -101.697 & 0.813502 \\
1996 & 7745.215 & 0.810134 & -40.8787 & 0.726127 \\
1997 & 7659.028 & 0.808499 & -29.8292 & 0.696327 \\
1998 & 7586.125 & 0.815514 & -38.8999 & 0.709374 \\
1999 & 7210.478 & 0.826384 & -39.4444 & 0.718787 \\
2000 & 5209.664 & 0.844991 & 30.12606 & 0.713394 \\
2001 & 3988.66 & 0.873058 & 40.02221 & 0.751543 \\
2002 & 1995.388 & 0.921447 & 50.72065 & 0.793232 \\
2003 & 1430.173 & 0.933924 & 55.81661 & 0.844306 \\
2004 & 1731.066 & 0.976354 & -4.75576 & 0.983 \\
2005 & $-15,402.8$ & 1.450602 & -60.6428 & 0.989761 \\
2006 & 9540.945 & 0.789723 & -14.7269 & 0.875059 \\
2007 & $23,993.95$ & 0.425805 & -5.93882 & 0.461446 \\
2008 & $42,433.49$ & -0.01383 & -12.1964 & 0.898117 \\
2009 & $39,604.67$ & 0.056022 & -12.8044 & 0.851664 \\
2010 & $19,887.09$ & 0.546172 & -14.9758 & 0.183346 \\
2011 & -4457.03 & 1.159738 & -24.3561 & 0.489499 \\
\hline
\end{tabular}

\begin{tabular}{llllll}
\hline Year & Actual & $\begin{array}{l}\text { World } \\
\text { demand }\end{array}$ & $\begin{array}{l}\text { Non- } \\
\text { OPEC } \\
\text { production }\end{array}$ & $\begin{array}{l}\text { Demand } \\
\text { OPEC }\end{array}$ & $\begin{array}{l}\text { Forecasted } \\
\text { price }\end{array}$ \\
\hline 1986 & 15.03 & $56,325.61$ & $38,453.61$ & 17,872 & DNE \\
1987 & 19.17 & $56,650.07$ & $38,640.75$ & $18,009.32$ & DNE \\
1988 & 15.98 & $58,696.86$ & $38,652.86$ & 20,044 & DNE \\
1989 & 19.64 & $59,801.83$ & $38,023.25$ & $21,778.59$ & DNE \\
1990 & 24.47 & $60,496.75$ & $37,563.68$ & $22,933.07$ & DNE \\
1991 & 21.50 & $60,127.63$ & $37,255.58$ & $22,872.05$ & DNE \\
1992 & 20.56 & $60,100.2$ & $35,897.92$ & $24,202.28$ & 21.94895 \\
1993 & 18.45 & $60,172.95$ & $35,210.09$ & $24,962.86$ & 21.54681 \\
1994 & 17.19 & $61,173.47$ & $35,783.9$ & $25,389.57$ & 20.28092 \\
1995 & 18.44 & $62,433.68$ & $36,376.1$ & $26,057.58$ & 19.03475 \\
1996 & 22.11 & $63,818.23$ & $37,228.31$ & $26,589.92$ & 18.89789 \\
1997 & 20.61 & $65,805.95$ & $37,856.04$ & $27,949.92$ & 19.88638 \\
\hline
\end{tabular}




\begin{tabular}{|c|c|c|c|c|c|}
\hline Year & Actual & $\begin{array}{l}\text { World } \\
\text { demand }\end{array}$ & $\begin{array}{l}\text { Non- } \\
\text { OPEC } \\
\text { production }\end{array}$ & $\begin{array}{l}\text { Demand } \\
\text { OPEC }\end{array}$ & $\begin{array}{l}\text { Forecasted } \\
\text { price }\end{array}$ \\
\hline 1998 & 14.45 & $67,031.77$ & $37,985.36$ & $29,046.41$ & 19.6061 \\
\hline 1999 & 19.26 & $65,967.39$ & $38,064.91$ & $27,902.49$ & 17.73101 \\
\hline 2000 & 30.30 & $68,526.65$ & $38,820.06$ & $29,706.59$ & 18.97899 \\
\hline 2001 & 25.95 & $68,131.91$ & $39,296.32$ & $28,835.6$ & 20.67131 \\
\hline 2002 & 26.11 & $67,290.17$ & $40,112.02$ & $27,178.15$ & 21.76323 \\
\hline 2003 & 31.12 & $69,460.24$ & $40,788.42$ & $28,671.83$ & 21.98432 \\
\hline 2004 & 41.44 & $72,595.18$ & $41,323.25$ & $31,271.93$ & 22.87479 \\
\hline 2005 & 56.49 & $73,869.21$ & $41,096.58$ & $32,772.63$ & 42.51041 \\
\hline 2006 & 66.02 & $73,621.39$ & $41,138.02$ & $32,483.37$ & $\begin{array}{l}\text { Did not } \\
\text { converge }\end{array}$ \\
\hline 2007 & 72.32 & $73,330.83$ & $41,094.98$ & $32,235.84$ & 77.71237 \\
\hline 2008 & 99.57 & $74,301.01$ & $40,578.15$ & $33,722.85$ & 79.20913 \\
\hline 2009 & 61.65 & $73,120.57$ & $41,053.98$ & $32,066.59$ & 96.94699 \\
\hline 2010 & 79.40 & $74,887.25$ & $41,839.47$ & $33,047.78$ & 59.91716 \\
\hline 2011 & 94.88 & $74,908.39$ & $41,779.05$ & $33,129.34$ & $\begin{array}{l}\text { Did not } \\
\text { converge }\end{array}$ \\
\hline 2012 & 94.11 & $76,367.46$ & $42,023.42$ & $34,344.04$ & $\begin{array}{l}\text { Did not } \\
\text { converge }\end{array}$ \\
\hline 2013 & 97.91 & $76,448.82$ & $43,154.69$ & $33,294.13$ & $\begin{array}{l}\text { Did not } \\
\text { converge }\end{array}$ \\
\hline 2014 & 93.26 & $78,361.77$ & $45,021.37$ & $33,340.39$ & $\begin{array}{l}\text { Did not } \\
\text { converge }\end{array}$ \\
\hline 2015 & 48.69 & $80,755.05$ & $46,186.55$ & $34,568.5$ & 93.39229 \\
\hline 2016 & 43.15 & $80,841.61$ & $45,226.77$ & $35,614.84$ & 98.73517 \\
\hline 2017 & 50.88 & & & $35,467.53$ & $\begin{array}{l}\text { Did not } \\
\text { converge }\end{array}$ \\
\hline
\end{tabular}

The forecast error metrics for each of the three methods is as below:

\begin{tabular}{llcll}
\hline & MAD & MSE & MAPE & \multicolumn{1}{l}{ MPE } \\
\hline Method 1 & 23.45651 & 727.6283 & 0.838836 & -0.78215 \\
Method 2 & 83.82119 & $96,984.95$ & 1.025901 & -0.36583 \\
Method 3 & 28.91879 & 1909.927 & 0.485201 & 0.214237 \\
\hline
\end{tabular}

MAD (Mean Absolute Deviation) is the average of absolute forecast errors (The differences between actual and forecast values); MSE (Mean Squared Error) is the average of squared forecast errors; MAPE (Mean Absolute Percentage Error) is the average of absolute forecast errors divided by actual values; MPE (Mean Percentage Error) is the average of forecast errors divided by actual values.
As we felt, we could improve the results further, we decided to use a method that combines the above three models.

\section{Combination model}

Our Combination Model combines both Methods 1 and 3 because they had significantly lower errors than Method 2. We first calculated the forecasted values for the years 1991 through 2017 using both Methods 1 and 3. After obtaining the values of the forecasted crude oil prices, we compared them with the prices of the previous period. For example, we would compare the forecasted price of 1991 for Methods 1 and 3 with the actual price from 1990, and take the forecasted value that was closer to the actual price of the previous period. If a Method did not produce a forecast for the period in question, we would use the other method. Based on that comparison, the forecasted value of the period in question would be either Method 1 or 3 , depending on whichever Method produced a closer forecast to the previous period. Using this methodology, we obtained the below table of forecasted values:

The forecasted values obtained are given in the below table.

\begin{tabular}{llllll}
\hline Year & Actual & $\begin{array}{l}\text { Forecast } \\
\text { price } \\
\text { (Method } \\
\text { 1) }\end{array}$ & $\begin{array}{l}\text { Forecast } \\
\text { price } \\
\text { (Method } \\
\text { 3) }\end{array}$ & $\begin{array}{l}\text { Forecast } \\
\text { price } \\
\text { (combination) }\end{array}$ & Method \\
\hline 1986 & 15.03 & DNE & DNE & DNE & DNE \\
1987 & 19.17 & DNE & DNE & DNE & DNE \\
1988 & 15.98 & DNE & DNE & DNE & DNE \\
1989 & 19.64 & DNE & DNE & DNE & DNE \\
1990 & 24.47 & DNE & DNE & DNE & DNE \\
1991 & 21.50 & 25.34403 & DNE & 25.34403 & 1 \\
1992 & 20.56 & 23.49511 & 21.94895 & 21.94895 & 3 \\
1993 & 18.45 & 34.72071 & 21.54681 & 21.54681 & 3 \\
1994 & 17.19 & 40.22087 & 20.28092 & 20.28092 & 3 \\
1995 & 18.44 & 44.98176 & 19.03475 & 19.03475 & 3 \\
1996 & 22.11 & 51.01424 & 18.89789 & 18.89789 & 3 \\
1997 & 20.61 & 55.51825 & 19.88638 & 19.88638 & 3 \\
1998 & 14.45 & 64.28711 & 19.6061 & 19.6061 & 3 \\
1999 & 19.26 & 70.48958 & 17.73101 & 17.73101 & 3 \\
2000 & 30.30 & 63.97958 & 18.97899 & 18.97899 & 3 \\
2001 & 25.95 & 73.32451 & 20.67131 & 20.67131 & 3 \\
2002 & 26.11 & 68.49023 & 21.76323 & 21.76323 & 3 \\
2003 & 31.12 & 59.08099 & 21.98432 & 21.98432 & 3 \\
2004 & 41.44 & 66.11404 & 22.87479 & 22.87479 & 3 \\
2005 & 56.49 & 76.30616 & 42.51041 & 42.51041 & 3 \\
\hline & & & & &
\end{tabular}




\begin{tabular}{|c|c|c|c|c|c|}
\hline Year & Actual & $\begin{array}{l}\text { Forecast } \\
\text { price } \\
\text { (Method } \\
\text { 1) }\end{array}$ & $\begin{array}{l}\text { Forecast } \\
\text { price } \\
\text { (Method } \\
\text { 3) }\end{array}$ & $\begin{array}{l}\text { Forecast } \\
\text { price } \\
\text { (combination) }\end{array}$ & Method \\
\hline 2006 & 66.02 & 82.25424 & $\begin{array}{l}\text { Did not } \\
\text { Converge }\end{array}$ & 82.25424 & 1 \\
\hline 2007 & 72.32 & 81.14913 & 77.71237 & 77.71237 & 3 \\
\hline 2008 & 99.57 & 80.37065 & 79.20913 & 79.20913 & 3 \\
\hline 2009 & 61.65 & 86.75108 & 96.94699 & 96.94699 & 3 \\
\hline 2010 & 79.40 & 79.8512 & 59.91716 & 59.91716 & 3 \\
\hline 2011 & 94.88 & 81.26497 & $\begin{array}{l}\text { Did not } \\
\text { Converge }\end{array}$ & 81.26497 & 1 \\
\hline 2012 & 94.11 & 81.68731 & $\begin{array}{l}\text { Did not } \\
\text { Converge }\end{array}$ & 81.68731 & 1 \\
\hline 2013 & 97.91 & 84.62633 & $\begin{array}{l}\text { Did not } \\
\quad \text { Converge }\end{array}$ & 84.62633 & 1 \\
\hline 2014 & 93.26 & 78.20684 & $\begin{array}{l}\text { Did not } \\
\text { Converge }\end{array}$ & 78.20684 & 1 \\
\hline 2015 & 48.69 & 72.12382 & 93.39229 & 93.39229 & 3 \\
\hline 2016 & 43.15 & 70.24915 & 98.73517 & 70.24915 & 1 \\
\hline 2017 & 50.88 & 76.10744 & $\begin{array}{l}\text { Did not } \\
\text { Converge }\end{array}$ & 76.10744 & 1 \\
\hline
\end{tabular}

The forecast error metrics for the Combination Method are as below:

\begin{tabular}{lllll}
\hline & MAD & MSE & MAPE & MPE \\
\hline $\begin{array}{c}\text { Combination } \\
\text { method }\end{array}$ & 12.67652 & 280.9213 & 0.259782 & -0.02787 \\
\hline
\end{tabular}

The errors for this Combination Method are significantly lower than any of the other three methods, and this method was chosen for prediction of our forecasted values.

Forecasting monthly crude oil prices

The monthly crude oil price has a high co-relation to the annual crude oil price, and hence forecasting the monthly crude oil price is performed using a simple regression utilizing the annual crude oil price. The equation can be summarized as below:

$P^{\text {month }}=\alpha+\beta\left(P^{\text {annual }}\right)$

where $\mathrm{P}^{\text {month }}$ is the monthly crude oil price and $\mathrm{P}^{\text {annual }}$ is the annual crude oil price.

In order to predict monthly crude oil price, the annual crude oil price must be known as the monthly crude oil price is dependent on the annual crude oil price. But, as we do not know the actual annual crude oil price until the year is over, we use the forecasted annual crude oil price. Since, in the previous section, the method of deriving the forecasted annual crude oil price was introduced, the forecasted annual crude oil price can be used as the annual crude oil price in Eq. 8 . The table below lists the coefficients for each month of the year along with their corresponding R-square values based on a simple regression of the monthly data values from 1987 to 2017.

\begin{tabular}{lcll}
\hline Month & Intercept & X-Variable & R Square \\
\hline January & 1.798174388 & 1.01516493 & 0.955660642 \\
February & 3.11239183 & 0.982188395 & 0.956459646 \\
March & 3.617377098 & 0.934706194 & 0.975288062 \\
April & 3.762271009 & 0.904444111 & 0.973271328 \\
May & 3.112401377 & 0.910227427 & 0.965484705 \\
June & 4.161813726 & 0.879087694 & 0.947909655 \\
July & 4.202809267 & 0.870103136 & 0.966824892 \\
August & 1.464031469 & 0.933482055 & 0.979218601 \\
September & -0.290228973 & 0.975941258 & 0.980763525 \\
October & -1.622652992 & 1.020355323 & 0.94178581 \\
November & 1.112219771 & 0.983138895 & 0.875008791 \\
December & 4.393831192 & 0.932305451 & 0.790770935 \\
\hline
\end{tabular}

Applying the coefficients from the table above to Eq. 8 to forecast the monthly crude oil prices, we achieved the following table of monthly forecasted prices: 


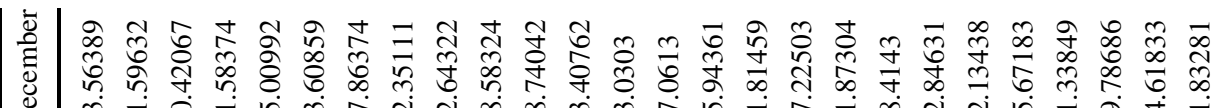

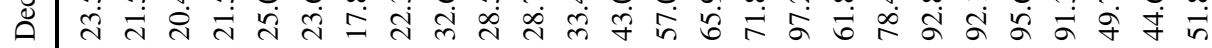

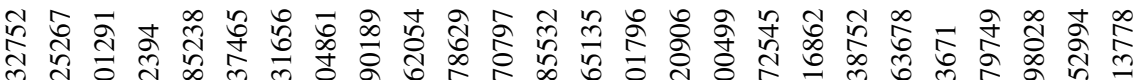

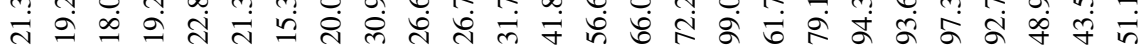

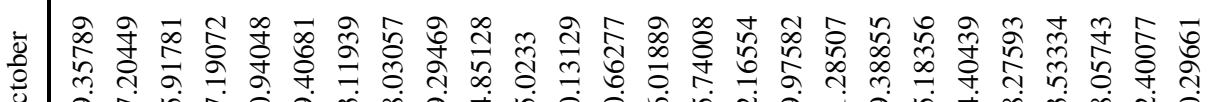

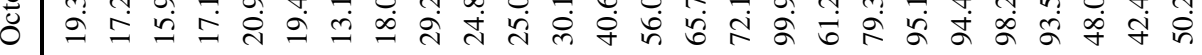
产

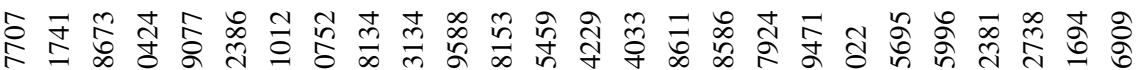

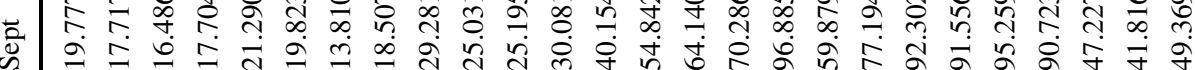

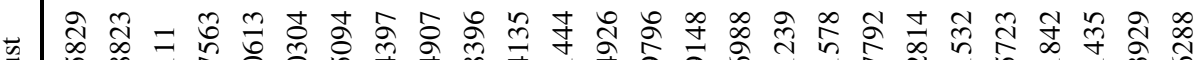

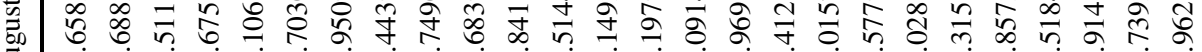

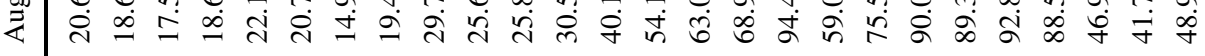

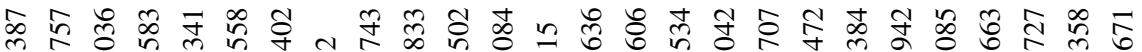

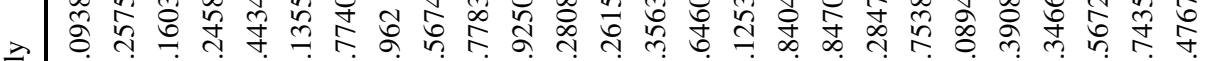

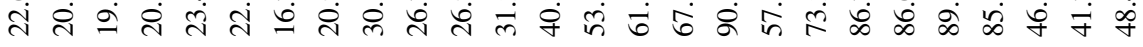
च ๙ तิ

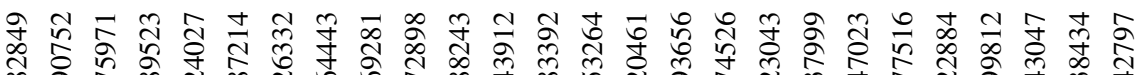

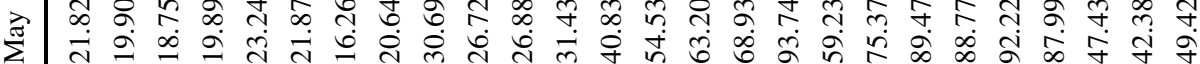
宽

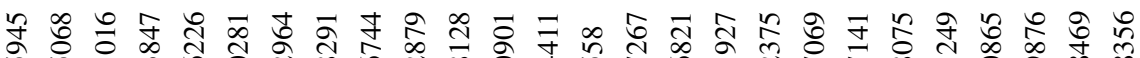

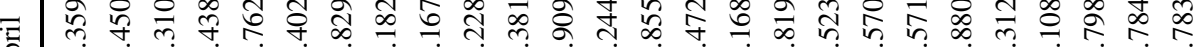

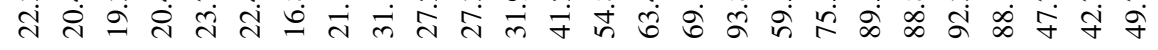

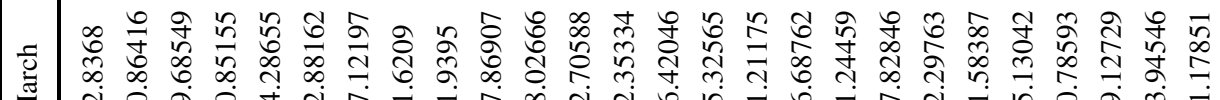
य ते तें

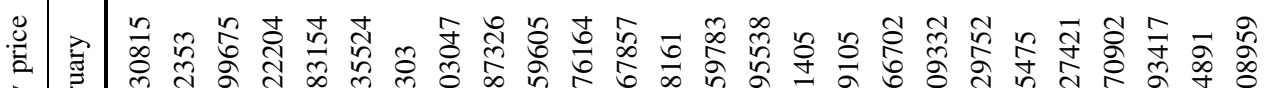
有

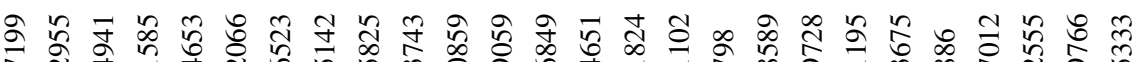

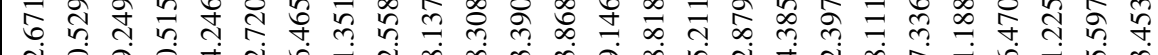

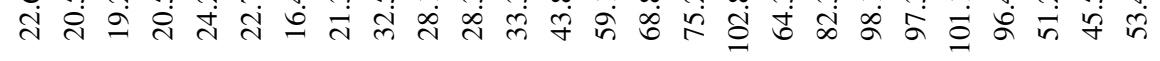

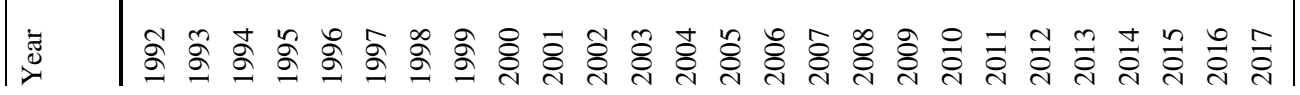


The above monthly forecasts are then compared with the actual data on monthly crude oil prices (from Federal Reserve Economic data), and the forecast error metrics calculated are as below:

\begin{tabular}{lllll}
\hline \multicolumn{5}{l}{ Error table: monthly crude oil price } \\
\hline & MAD & MSE & MAPE & MPE \\
\hline $1992-2017$ & 5.658286 & 82.1163 & 0.124643 & -0.03888 \\
\hline
\end{tabular}

Evaluation of the Forecast Model—Annual Price

To evaluate the forecast models, the actual crude oil prices from year 1991 to 2017 are compared with the forecasted price obtained from the models. We tested several forecasting methods and the best method was a combination model. As seen in the earlier section, the MAD is 12.68 , meaning that on average, the forecast price is 12.68 cents above or below the actual price. The MAPE is $25.97 \%$, meaning that on an average, the difference between actual and forecast price is about $25.97 \%$ of actual price. Finally, the MPE is $-2.78 \%$ which shows that a small percentage of over forecast resulted with the combination model. Overall, the results are promising and it shows the strength of our forecasting models in predicting the price of crude oil.

Following this, we estimated the forecasts of the oil prices at a monthly level and calculated the forecast error metrics. The MAD, MAPE and MPE values are $5.66,12.46 \%$ and $3.89 \%$, respectively, which shows our model is promising again at a monthly level.

Comparison of our methods to Box-Jenkins (ARIMA) models

We implemented ARIMA models through MINITAB 19 software. The plot of the data of the oil prices from 1986 to 2017 showed an increasing trend. This was further confirmed through the observation that the first several autocorrelations are persistently large and trailed off to zero rather slowly. We differenced the data to eliminate the trend and create a stationary series. A plot of the differenced data appeared to vary about a fixed level.
The sample autocorrelations and the sample partial autocorrelations for the differenced data are then plotted. Comparing the autocorrelations with their error limits, the only significant autocorrelation was at lag 1 . Similarly, only the lag 2 partial autocorrelation was significant. The autocorrelations appear to cut off after lag 1, indicating MA (1) behavior. At the same time, the partial autocorrelations appear to cut off after lag 2, indicating AR (2) behavior. Neither pattern appears to die out in a declining manner at low lags. So, we decided to fit both ARIMA $(2,1,0)$ and ARIMA $(0,1,1)$ models to our data.

We compared the ARIMA models with the Combination Method discussed earlier in our paper. The forecast error metrics for the Combination Method are as below and are based on the best of the Method 1 and Method 3 presented in the paper (please refer to earlier discussion on this in the paper).

\begin{tabular}{lllll}
\hline & MAD & MSE & MAPE & MPE \\
\hline $\begin{array}{c}\text { Combination } \\
\text { Method }\end{array}$ & 12.67652 & 280.9213 & 0.259782 & -0.02787 \\
\hline
\end{tabular}

Note that, our Method 1 methodology involves running a regression on all the data from 1987 to 2017 to obtain the coefficients used for forecasting the price of oil for each of the year's from 1987 to 2017.

Our Method 3 methodology involves running a regression of past 5 years' of data to obtain the coefficients used for forecasting the price of oil for the next year. For example, the coefficients for 1992 were from a regression of the data from 1987 to 1991. The coefficients for 2017 were from a regression of the data from 2012 to 2016. When forecasting the price of crude oil for a certain year with Method 3, the coefficients used are the coefficients that were associated with the previous year. For example, forecasting the price of crude oil for year 1992 would use the coefficients for 1991.

We cannot apply Method 1 type static data analysis for ARIMA models and thus use only the type of data analysis used in Method 3 for the forecast of oil prices from the $\operatorname{ARIMA}(2,1,0)$ and $\operatorname{ARIMA}(0,1,1)$ models.

To be clear, we use the past five years' of data to forecast the price of oil for the next time period. 
We present below the results for the ARIMA $(2,1$, $0)$ and ARIMA $(0,1,1)$ models. For example, the forecast of oil price for 1992 is based on the data from 1987 to 1991 . The forecast of oil price for 2017 is based on the data from 2012 to 2016, etc.

We next present the results from the ARIMA $(2,1$, $0)$ and $\operatorname{ARIMA}(0,1,1)$ models in the below tables.

$\operatorname{ARIMA}(2,1,0)$ Forecast Results with five past five periods of data for next period forecast

\begin{tabular}{|c|c|c|c|}
\hline Year & Time & Actual & Forecasts \\
\hline 1986 & 1 & 15.03 & - \\
\hline 1987 & 2 & 19.17 & - \\
\hline 1988 & 3 & 15.98 & - \\
\hline 1989 & 4 & 19.64 & - \\
\hline 1990 & 5 & 24.47 & - \\
\hline 1991 & 6 & 21.50 & 16.9584 \\
\hline 1992 & 7 & 20.56 & 15.9197 \\
\hline 1993 & 8 & 18.45 & 23.7565 \\
\hline 1994 & 9 & 17.19 & 19.7446 \\
\hline 1995 & 10 & 18.44 & 15.0828 \\
\hline 1996 & 11 & 22.11 & 20.9461 \\
\hline 1997 & 12 & 20.61 & 25.6314 \\
\hline 1998 & 13 & 14.45 & 16.714 \\
\hline 1999 & 14 & 19.26 & 14.8582 \\
\hline 2000 & 15 & 30.30 & 23.4524 \\
\hline 2001 & 16 & 25.95 & 26.024 \\
\hline 2002 & 17 & 26.11 & 14.029 \\
\hline 2003 & 18 & 31.12 & 30.234 \\
\hline 2004 & 19 & 41.44 & 22.8305 \\
\hline 2005 & 20 & 56.49 & 56.7333 \\
\hline 2006 & 21 & 66.02 & 72.7245 \\
\hline 2007 & 22 & 72.32 & 65.4209 \\
\hline 2008 & 23 & 99.57 & 72.7825 \\
\hline 2009 & 24 & 61.65 & 105.872 \\
\hline 2010 & 25 & 79.40 & 97.6857 \\
\hline 2011 & 26 & 94.88 & 96.4187 \\
\hline 2012 & 27 & 94.11 & 58.5503 \\
\hline 2013 & 28 & 97.91 & 78.9061 \\
\hline 2014 & 29 & 93.26 & 101.481 \\
\hline 2015 & 30 & 48.69 & 97.0379 \\
\hline 2016 & 31 & 43.15 & -14 \\
\hline 2017 & 32 & 50.88 & 86.321 \\
\hline
\end{tabular}

$\operatorname{ARIMA}(0,1,1)$ Forecast results with five past five periods of data for next period forecast

\begin{tabular}{|c|c|c|c|}
\hline Year & Time & Actual & Forecasts \\
\hline 1986 & 1 & 15.03 & - \\
\hline 1987 & 2 & 19.17 & - \\
\hline 1988 & 3 & 15.98 & - \\
\hline 1989 & 4 & 19.64 & - \\
\hline 1990 & 5 & 24.47 & - \\
\hline 1991 & 6 & 21.50 & 23.0434 \\
\hline 1992 & 7 & 20.56 & 21.0656 \\
\hline 1993 & 8 & 18.45 & 20.8095 \\
\hline 1994 & 9 & 17.19 & 20.4972 \\
\hline 1995 & 10 & 18.44 & 17.3419 \\
\hline 1996 & 11 & 22.11 & 19.2997 \\
\hline 1997 & 12 & 20.61 & 24.1962 \\
\hline 1998 & 13 & 14.45 & 20.6595 \\
\hline 1999 & 14 & 19.26 & 11.5126 \\
\hline 2000 & 15 & 30.30 & 18.4863 \\
\hline 2001 & 16 & 25.95 & 34.5257 \\
\hline 2002 & 17 & 26.11 & 24.3153 \\
\hline 2003 & 18 & 31.12 & 26.1288 \\
\hline 2004 & 19 & 41.44 & 28.5115 \\
\hline 2005 & 20 & 56.49 & 47.2823 \\
\hline 2006 & 21 & 66.02 & 64.0383 \\
\hline 2007 & 22 & 72.32 & 68.4805 \\
\hline 2008 & 23 & 99.57 & 76.7584 \\
\hline 2009 & 24 & 61.65 & 118.45 \\
\hline 2010 & 25 & 79.40 & 73.4083 \\
\hline 2011 & 26 & 94.88 & 74.0308 \\
\hline 2012 & 27 & 94.11 & 85.7632 \\
\hline 2013 & 28 & 97.91 & 88.5758 \\
\hline 2014 & 29 & 93.26 & 102.578 \\
\hline 2015 & 30 & 48.69 & 94.0001 \\
\hline 2016 & 31 & 43.15 & 19.3672 \\
\hline 2017 & 32 & 50.88 & 44.9767 \\
\hline
\end{tabular}

The forecast error metrics for each of the two methods are as below: 


\begin{tabular}{lllll}
\hline & MAD & MSE & MAPE & \multicolumn{1}{l}{ MPE } \\
\hline $\begin{array}{c}\text { ARIMA } \\
(2,1,0)\end{array}$ & 14.08033 & 456.8168 & 0.296836 & 0.02373 \\
$\begin{array}{c}\text { ARIMA }(0, \\
1,1)\end{array}$ & 10.84226 & 287.6069 & 0.238679 & -0.00596 \\
\hline
\end{tabular}

Comparing the above solutions to our Combination Method below, we infer that our Combination Method performs better than ARIMA $(2,1,0)$ across all metrics, and is better than ARIMA $(0,1,1)$ on the MSE metric. ARIMA $(0,1,1)$ performs slightly better than our Combination Method on the MAD, MAPE and MPE metrics.

\begin{tabular}{lllll}
\hline & MAD & MSE & MAPE & MPE \\
\hline $\begin{array}{l}\text { Combination } \\
\text { Method }\end{array}$ & 12.67652 & 280.9213 & 0.259782 & -0.02787 \\
\hline
\end{tabular}

Note that, we also estimated the forecasts of the oil prices at a monthly level based on our annual forecasts of oil prices from our Combination Method and the calculated forecast error metrics are as follows (also presented earlier in the paper).

Error table: monthly crude oil price

\begin{tabular}{lllll}
\hline & MAD & MSE & MAPE & MPE \\
\hline $1992-2017$ & 5.658286 & 82.1163 & 0.124643 & -0.03888 \\
\hline
\end{tabular}

These numbers are even more promising and hence show the viability of our approach compared to traditional methodology such as the ARIMA models.

\section{Conclusions}

Although the overall results of our forecast models are promising, one of the limitations of our model is that it cannot predict the price changes caused by factors other than predictor variables that are used in the model. These factors include war, natural disaster, human expectation, and government interference. When one of these factors exists, the forecasted price may deviate from the actual price.

The purpose of the forecast model is to predict OPEC's behavior of setting oil price.

Behaviors may change from time to time. Therefore, the regression equation should be updated frequently to maintain the model's accuracy.

In summary, our forecast model is a good predictor of oil price. The data required are readily available, the number of variables is small, the forecast process is easy to follow, and the cost is very low; even individuals can afford it. Moreover, our model forecasts both annual and monthly oil price. Managers can use annual forecast price to develop long-term operation plans and monthly price to make short-term operation decisions. We hope that this model will help companies and management to lower costs, increase profit and gain advantage over their competitors.

Acknowledgements Regarding the data used in this paper, we will make the "Data available on request from the Authors" following the publication of this paper. At that point, all data will be placed online at the author's website.

\section{References}

Adelman MA (1990) Mineral depletion, with special reference to petroleum. Rev Econ Stat 72:1-10

Adelman MA (1993) Modeling world oil supply. Energy J 14:1-32

Al-Fattah SM (2019) Artificial intelligence approach for modeling and forecasting oil-price volatility. SPE Res Eval Eng 22:817-826

Alquist R et al (2011) Forecasting the price of oil. Federal Reserve Board, July 2011

An J, Mikhaylov A, Moiseev N (2019) Oil Price predictors: machine learning approach. Int $\mathrm{J}$ Energy Econ Policy 9(5):1-6

Bacon R (1991) Modeling the price of oil. Oxf Rev Econ Policy 7:17-34

Baumol WJ, Quandt RE (1964) Rules of thumb and optimally imperfect decision. Am Econ Rev 54:23-26

Beckers B, Beidas-Strom S (2015) Forecasting the nominal Brent oil price with VARs-one model fits all? IMF, International Monetary Fund, 25 Nov 2015

Cartlon DW, Perloff JM (1990) Modern industrial organization. Scott, Foesman and Company Press

Devarajan S, Fisher AC (1981) Hotelling economics of exhaustible resources: fifty years later. J Econ Lit XIX:65-73

Dritsaki C (2018) The performance of hybrid ARIMA-GARCH modeling and forecasting oil price. Int $\mathrm{J}$ Energy Econ Policy 8(3):14-21 
Energy Modeling Forum (1992) International oil supplies and demands. EMF Report 11, 2., Stanford University, USA

Funk C (2018) Forecasting the real price of oil-time-variation and forecast combination. Energy Econ 76:288-302

Gately D (1983) OPEC: retrospective and prospects: 1973-1990. Eur Econ Rev 21:313-331

Hotelling H (1931) The economics of exhaustible resources. J Polit Econ 39:137-175

Houthakker HS (1983) Whatever happened to the energy crisis? Energy J 4:1-8

Kulkarni S, Haidar I (2009) Forecasting model for crude oil price using artificial neural networks and commodity futures prices. Int J Comput Sci Inf Secur 2(1):1-9

Manescu C, Van Robays I (2014) Forecasting the Brent oil price: addressing time-variation in forecasting performance. European Central Bank, Sept. 2014

Moshiri S, Foroutan F (2005) Forecasting nonlinear crude oil futures prices. Energy J 27:81-95

Powell SG (1990) The target capacity utilization model of OPEC and the dynamics of the world oil market. Energy $\mathbf{J}$ 11:27-63
Scherer FM, Ross D (1990) Industrial market structure and economic performance. Houghton Mifflin Company Press, Boston

Stanford Research Institute (1991) 1991 Oil report knowledge base. Stanford University, USA

Sterman JD (1987) System simulation expectation formation in behavior simulation models. Behav Sci 32:190-211

Sterman JD (1989) Modeling managerial behavior: misperceptions of feedback in a dynamic decision making experiment. Manag Sci 35:321-339

Suranovic SM (1993) Does a target capacity utilization rule fulfill OPEC's economic objective? Energy Econ 15:71-79

Wang S, Yu L, Lai K (2005) Crude oil price forecasting with TEI@Imethodology. J Syst Sci Complex 18(2):145-166

Tussing AR, Harris MJ (1992) Energy shock, surprise and forecasting failure. OPEC Rev 16:63-77

Publisher's Note Springer Nature remains neutral with regard to jurisdictional claims in published maps and institutional affiliations. 